\title{
Mechanisms Mediating High-Molecular-Weight Hyaluronan-Induced Antihyperalgesia
}

\author{
Ivan J.M. Bonet, ${ }^{1}{ }^{\circledR}$ Dionéia Araldi, ${ }^{1}{ }^{\circledR}$ Eugen V. Khomula, ${ }^{1}$ Oliver Bogen, ${ }^{1}{ }^{\oplus}$ Paul G. Green, ${ }^{2}$ and \\ (ㄱ) Jon D. Levine ${ }^{3}$ \\ ${ }^{1}$ Department of Oral and Maxillofacial Surgery, and Division of Neuroscience, University of California, San Francisco, San Francisco, California \\ $94143,{ }^{2}$ Departments of Preventative and Restorative Dental Sciences and Oral and Maxillofacial Surgery, and Division of Neuroscience, University \\ of California, San Francisco, San Francisco, California 94143, and ${ }^{3}$ Departments of Medicine and Oral and Maxillofacial Surgery, and Division of \\ Neuroscience, UCSF Pain and Addiction Research Center, University of California, San Francisco, San Francisco, California 94143
}

We evaluated the mechanism by which high-molecular-weight hyaluronan (HMWH) attenuates nociceptor sensitization, in the setting of inflammation. HMWH attenuated mechanical hyperalgesia induced by the inflammatory mediator prostaglandin $\mathrm{E} 2\left(\mathrm{PGE}_{2}\right)$ in male and female rats. Intrathecal administration of an oligodeoxynucleotide antisense (AS-ODN) to mRNA for cluster of differentiation 44 (CD44), the cognate hyaluronan receptor, and intradermal administration of A5G27, a CD44 receptor antagonist, both attenuated antihyperalgesia induced by HMWH. In male rats, HMWH also signals via Toll-like receptor 4 (TLR4), and AS-ODN for TLR4 mRNA administered intrathecally, attenuated HMWH-induced antihyperalgesia. Since HMWH signaling is dependent on CD44 clustering in lipid rafts, we pretreated animals with methyl- $\beta$-cyclodextrin $(\mathrm{M} \beta \mathrm{CD})$, which disrupts lipid rafts. $\mathrm{M} \beta \mathrm{CD}$ markedly attenuated HMWH-induced antihyperalgesia. Inhibitors for components of intracellular signaling pathways activated by CD44, including phospholipase C and phosphoinositide 3-kinase (PI3K), also attenuated $\mathrm{HMWH}$-induced antihyperalgesia. Furthermore, in vitro application of $\mathrm{HMWH}$ attenuated $\mathrm{PGE}_{2}$-induced sensitization of tetrodotoxin-resistant sodium current, in small-diameter dorsal root ganglion neurons, an effect that was attenuated by a PI3K inhibitor. Our results indicate a central role of CD44 signaling in HMWH-induced antihyperalgesia and suggest novel therapeutic targets, downstream of $\mathrm{CD} 44$, for the treatment of pain generated by nociceptor sensitization.

Key words: antihyperalgesia; cluster of differentiation 44 (CD44); high-molecular-weight hyaluronan (HMWH); hyaluronan; hyperalgesia; prostaglandin $\mathrm{E} 2\left(\mathrm{PGE}_{2}\right)$

\section{Significance Statement}

High-molecular-weight-hyaluronan (HMWH) is used to treat osteoarthritis and other pain syndromes. In this study we demonstrate that attenuation of inflammatory hyperalgesia by HMWH is mediated by its action at cluster of differentiation 44 (CD44) and activation of its downstream signaling pathways, including RhoGTPases (RhoA and Rac1), phospholipases (phospholipases $\mathrm{C} \varepsilon$ and $\mathrm{C} \gamma \mathrm{1}$ ), and phosphoinositide 3-kinase, in nociceptors. These findings contribute to our understanding of the antihyperalgesic effect of HMWH and support the hypothesis that CD44 and its downstream signaling pathways represent novel therapeutic targets for the treatment of inflammatory pain.

\section{Introduction}

Intra-articular high-molecular-weight hyaluronan (HMWH) is used clinically to treat osteoarthritis pain (Dougados et al., 1993;

\footnotetext{
Received Jan. 21, 2020; revised July 1, 2020; accepted July 4, 2020

Author contributions: I.J.M.B., P.G.G., and J.D.L. designed research; I.J.M.B., D.A., E.V.K., and 0.B. performed research; I.J.M.B., D.A., E.V.K., and 0.B. analyzed data; I.J.M.B., D.A., E.V.K., O.B., P.G.G., and J.D.L. wrote the paper.

The authors declare no competing financial interests.

This study was funded by National Institutes of Health Grant AR-075334. We thank Monica Le and Samantha Stevens for technical assistance.

Correspondence should be addressed to Jon D. Levine at Jon.Levine@ucsf.edu

https://doi.org/10.1523/JNEUROSCI.0166-20.2020

Copyright $\odot 2020$ the authors
}

Altman and Moskowitz, 1998; Cohen et al., 2008; Huang et al., 2011; Triantaffilidou et al., 2013). While it is generally considered that this therapeutic effect is mediated by its viscoelastic properties (Radin et al., 1970; Unsworth et al., 1975; Elmorsy et al., 2014; Cowman et al., 2015), recent evidence supports the suggestion that HMWH-induced antihyperalgesia is substantially related to its effects on nociceptor function (Gomis et al., 2007; Ferrari et al., 2016a, 2018). However, the mechanism by which HMWH produces antihyperalgesia remains poorly understood.

Hyaluronan (HA), a negatively charged linear polymer of a disaccharide composed of glucuronate and $\mathrm{N}$-acetylglucosamine, is a major component of the extracellular matrix (Toole, 2009; Tavianatou et al., 2019). While HA is a simple repeating disaccharide, its biological effects are complex (Karousou et al., 2017; 
Wight, 2017, 2018; Johnson et al., 2018). For example, HA can have different, and in some cases opposite, effects. For example, HA can be proinflammatory or anti-inflammatory, depending on its molecular weight (McKee et al., 1996; Yamawaki et al., 2009; Campo et al., 2010; Mizrahy et al., 2011; Kataoka et al., 2013; Furuta et al., 2017; Wu et al., 2018). We have suggested that low-molecular-weight HA (LMWH) and HMWH can act at nociceptors to produce prohyperalgesic and antihyperalgesic effects, respectively (Ferrari et al., 2018).

HMWH binds to and signals via several membrane receptors including, cluster of differentiation 44 (CD44), receptor for HAmediated motility (RHAMM), and toll-like receptor 4 (TLR4; Vigetti et al., 2014; Tavianatou et al., 2019). The ability of HA to induce different CD44-dependent cell responses has been shown to be related to its molecular weight (Underhill, 1992; Tammi et al., 1998; Lesley et al., 2000; Louderbough and Schroeder, 2011; Padmanabhan and Gonzalez, 2012; Senbanjo and Chellaiah, 2017). For example, LMWH upregulates inflammation by stimulating the release of proinflammatory cytokines (McKee et al., 1996; Yamawaki et al., 2009; Campo et al., 2010), while HMWH is anti-inflammatory and immunosuppressant (Cuff et al., 2001; Mizrahy et al., 2011; Kataoka et al., 2013; Furuta et al., 2017; Wu et al., 2017). Further insight into the different effects of LMWH and HMWH has been provided by the observation that $\mathrm{HMWH}$, but not LMWH, signaling is dependent on lipid rafts. For example, high levels of cholesterol promote CD44 translocation into lipid rafts, which is required for HMWH signaling via CD44 (Murai, 2015; Yang et al., 2018), while disrupting lipid rafts (Foger et al., 2001; Ito et al., 2004; Ghatak et al., 2005) suppresses HMWH-induced CD44 clustering in subsequent activation of downstream-dependent signaling (Bourguignon et al., 2000, 2003), and LMWH does not induce CD44 clustering (Yang et al., 2012). Previously, we demonstrated that HMWH markedly attenuated mechanical hyperalgesia induced by LMWH (Ferrari et al., 2016a), and by diverse pronociceptive inflammatory mediators in male rats, as well as paclitaxel chemotherapy-induced neuropathic pain (Ferrari et al., 2018). These observations suggest that elucidating the mechanism by which HMWH attenuates nociceptor sensitization could identify novel targets for the treatment of pain.

CD44, considered the cognate HA receptor (Bourguignon, 2014; Bourguignon et al., 2014), has been proposed to mediate the effects of HA on nociceptors (Ferrari et al., 2016a). In this study, we focus on the role of nociceptor CD44 and its downstream signaling pathways in the antihyperalgesia induced by $\mathrm{HMWH}$, specifically the role of CD44 signaling molecules RhoA and Rac1, members of the Ras superfamily of small-molecularweight GTPases (e.g., RhoA and Rac1), which act as molecular switches alternating between GTP-bound and GDP-bound states (Bourguignon et al., 2014), to in turn activate phosphoinositide 3-kinase (PI3K).

\section{Materials and Methods}

Animals. All experiments were performed on female and male Sprague Dawley rats (weight, 220-400 g; Charles River Laboratories). Experimental animals were housed three per cage, under a $12 \mathrm{~h}$ light/dark cycle, in a temperature-controlled and humidity-controlled animal care facility of the University of California, San Francisco. Food and water were available ad libitum. Experimental protocols were approved by the Institutional Animal Care and Use Committee at the University of California, San Francisco, and adhered to the National Institutes of Health Guidelines for the Care and Use of Laboratory Animals. Effort was made to minimize the number of animals used and their suffering.
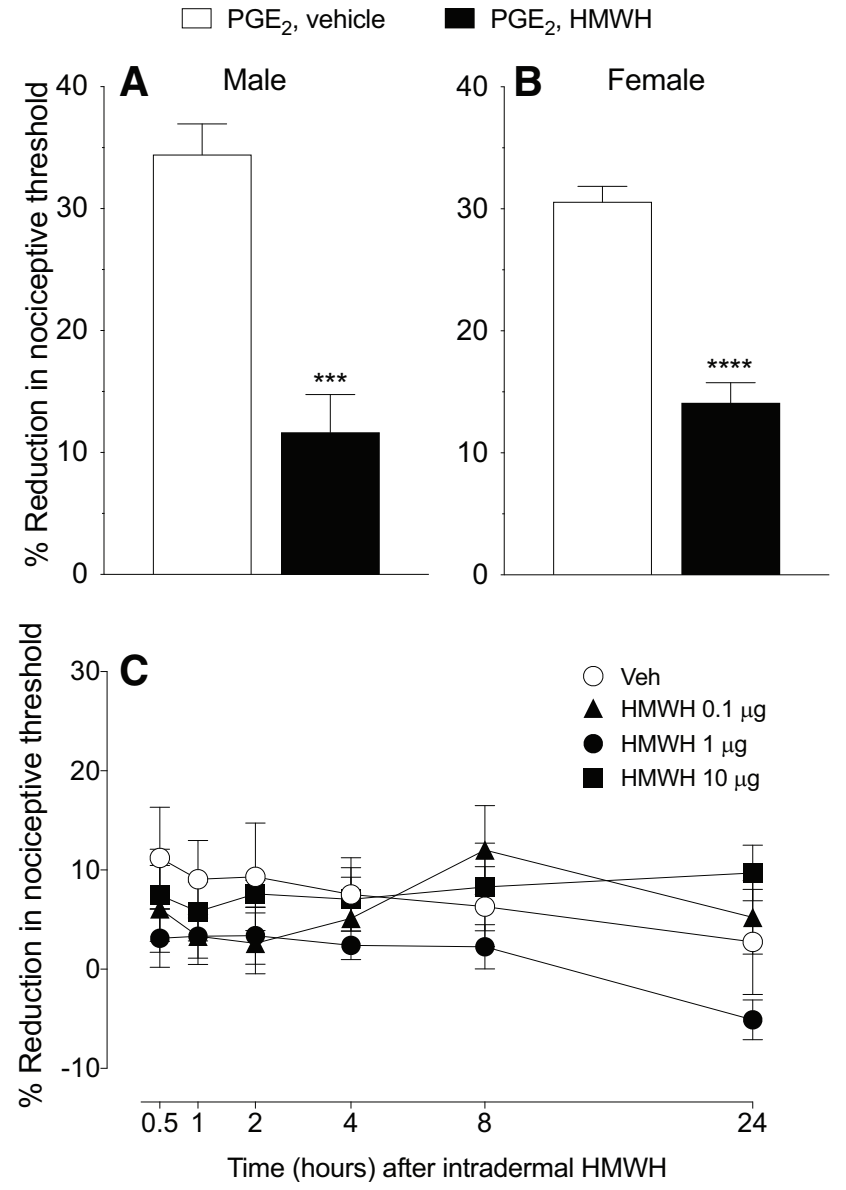

Figure 1. HMWH attenuates $\mathrm{PGE}_{2}$ hyperalgesia but did not alone affect the nociceptive threshold. $\boldsymbol{A}, \boldsymbol{B}$, Male and female rats received $\mathrm{PGE}_{2}(100 \mathrm{ng} / 5 \mu \mathrm{l}$, intradermally) on the dorsum of the hindpaw followed $10 \mathrm{~min}$ later by HMWH $(1 \mu \mathrm{g} / 5 \mu \mathrm{l})$ or vehicle $(5 \mu \mathrm{l})$ injected at the same site. The mechanical nociceptive threshold was then measured $40 \mathrm{~min}$ after intradermal $\mathrm{PGE}_{2}$. Measurement of mechanical nociceptive threshold showed a significant attenuation of $\mathrm{PGE}_{2}$ hyperalgesia in rats treated with $\mathrm{HMWH}\left(\boldsymbol{A} ; t_{(10)}=5.676\right.$, ${ }^{* *} p=0.0002$, when the vehicle-treated group was compared with the HMWH-treated group; unpaired Student's $t$ test; $\boldsymbol{B} ; t_{(10)}=7.860,{ }^{* * * *} p<0.0001$, when the vehicle-treated group was compared with the HMWH-treated group; unpaired Student's $t$ test). $n=6$ paws in each group. $\boldsymbol{C}$, Male rats received an intradermal injection of one of three doses of HMWH [0.1 $1 \mu \mathrm{g}$, black triangle; $1 \mu \mathrm{g}$, black circle; or $10 \mu \mathrm{g}$, black square; diluted in $5 \mu \mathrm{l}$ of saline) or vehicle (5 $\mu \mathrm{l}$, white circle). Mechanical nociceptive threshold was evaluated $0.5,1,2,4,8$, and $24 \mathrm{~h}$ after intradermal HMWH administration. The time course of the effect of HMWH on nociceptive threshold did not differ among the $0.1,1$, and $10 \mu \mathrm{g}$ doses, and did not affect the nociceptive threshold itself. Repeated-measures two-way ANOVA, followed by Tukey's multiple-comparison test, revealed no significant interaction among the groups (interaction: $F_{(15,100)}=1.168, p=0.3088$; time: $F_{(5,100)}=1.241, p=0.2959$; dose: $F_{(3,20)}=1.093$, $p=0.3750) . n=6$ paws in each group.

Measuring nociceptive threshold. Nociceptive testing was performed between 10:00 A.M. and 12:00 P.M., except for the experiments in Figure 1C, which were performed between 9:00 A.M. and 5:00 P.M. Mechanical nociceptive threshold was quantified using an Ugo Basile Analgesy-Meter (Stoelting), to perform the Randall-Selitto paw-withdrawal test. The Analgesy-Meter applies a linearly increasing mechanical force to the dorsum of the hindpaw of the rat, as previously described (Randall and Selitto, 1957; Taiwo et al., 1989; Taiwo and Levine, 1989). Rats were placed in cylindrical acrylic restrainers with lateral ports that allow extension of their hindlegs for nociceptive threshold testing, as previously described (Araldi et al., 2019), to acclimatize them to the experimental procedures.

Mechanical nociceptive threshold was defined as the force, in grams, at which the rat withdrew its paw. Baseline threshold was defined as the mean of three readings taken before the injection of test agents. Each experiment was performed on a different group of rats. Data are 

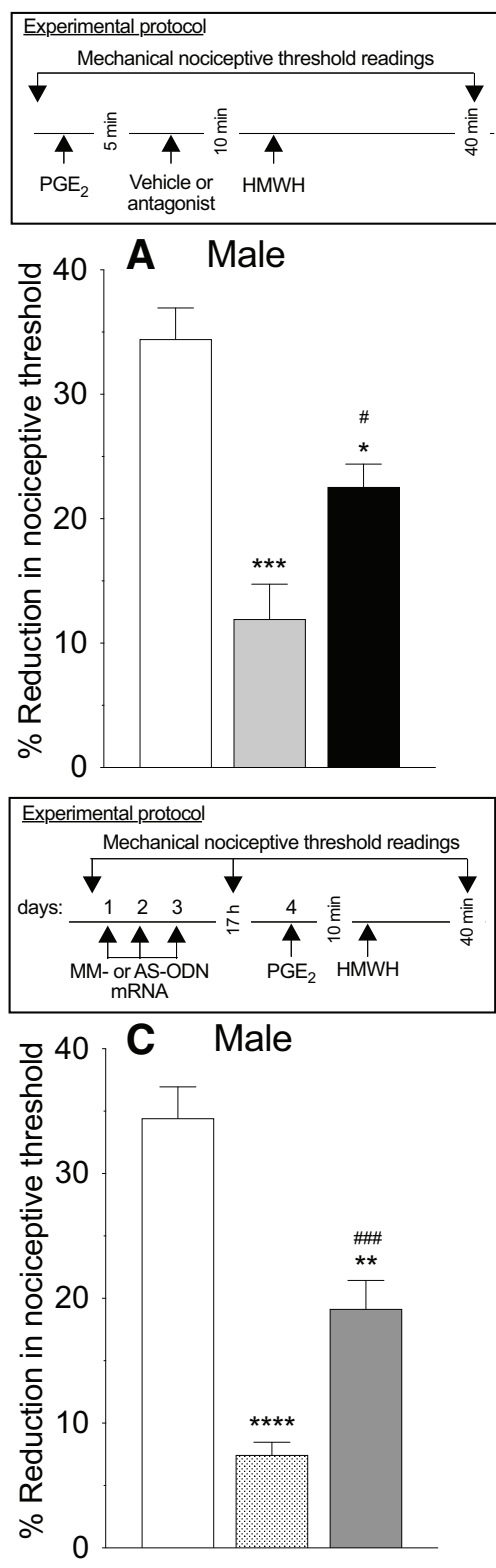

E
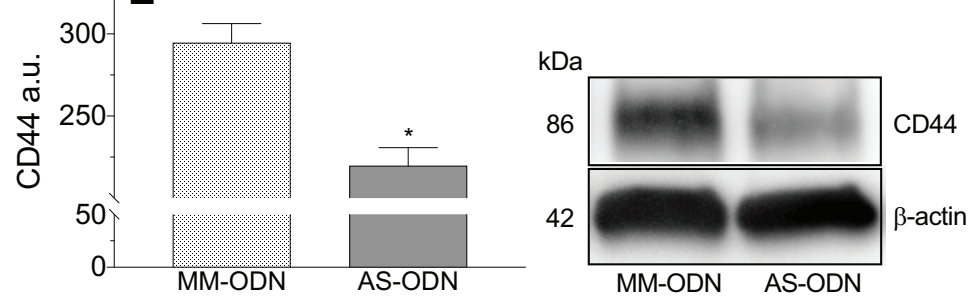

Figure 2. Reversal of $\mathrm{PGE}_{2}$ hyperalgesia by HMWH was attenuated by CD44 ODN antisense and a CD44 receptor antagonist. $A, B$, Male and female rats were treated intradermally with $\mathrm{PGE}_{2}(100 \mathrm{ng} / 2 \mu \mathrm{l})$, followed 5 min later by a $C D 44$ receptor antagonist (A5G27, $1 \mu \mathrm{g} / 2 \mu \mathrm{l})$ or vehicle $(2 \mu \mathrm{l})$ also injected intradermally. Ten minutes after $\mathrm{PGE}_{2}$, rats received intradermal HMWH $(1 \mu \mathrm{g} / 2 \mu \mathrm{l})$ and the mechanical nociceptive threshold was evaluated before and 40 min after intradermal PGE $_{2}$. In male rats that received a CD44 receptor antagonist, a significant attenuation in HMWH-induced antihyperalgesia was observed $\left(\boldsymbol{A} ; F_{(2,10)}=19.85, \# p=0.0344\right.$, when the CD44 receptor antagonist group plus the HMWH-treated group was compared with the vehicle group plus the HMWH-treated group; ${ }^{*} p=0.0191$, when the CD44 receptor antagonist plus HMWH-treated group was compared with the $\mathrm{PGE}_{2}$-treated group alone; ${ }^{* * *} p=0.0002$, when the vehicle group plus the HMWH-treated group was compared with $\mathrm{PGE}_{2}$-treated group alone 40 min after intradermal $\mathrm{PGE}_{2}$ administration; two-way ANOVA followed by Tukey's multiple-comparisons test); however, in female rats HMWH-induced antihyperalgesia was completely reversed in the group that received $C D 44$ antagonist receptor intradermally $\left(\boldsymbol{B} ; F_{(2,10)}=11.28, \# p=0.0127\right.$, when the CD44 receptor antagonist group plus the HMWH-treated group was compared with the vehicle group plus HMWH-treated group; ${ }^{* * *} p=0.0030$, when the vehicle group plus the HMWH-treated group was compared with the $\mathrm{PGE}_{2}$-treated group presented as the percentage change from baseline nociceptive threshold. Individuals performing the behavioral experiments (I.J.M.B. and D. A.) were blinded to interventions in the key experiments (Figs. 2, 3, 4, 5).

Drugs. The following drugs were used in this study: HMWH (hyaluronic acid sodium salt from Streptococcus pyogenes), from Calbiochem; prostaglandin E2 ( $\left.\mathrm{PGE}_{2}\right)$, methyl$\beta$-cyclodextrin ( $\mathrm{M} \beta \mathrm{CD})$, an Src inhibitor (SU6656), a MAPK/ERK inhibitor (U0126), PI3K inhibitors (wortmannin and LY294002), a phospholipase C (PLC) inhibitor (U73122), a Rho-associated kinase (ROK) inhibitor (Y27632), and a Rac1 inhibitor (NSC23766), all purchased from Sigma-Aldrich; and a CD44 antagonist (A5G27 [a peptide that binds to and inhibits CD44-dependent signaling]) from GenScript.

A stock solution of $\mathrm{PGE}_{2}$, dissolved in absolute ethanol to a concentration of $1 \mu \mathrm{g} / \mu \mathrm{l}$, was further diluted in $0.9 \% \mathrm{NaCl}$, immediately before experiments. The ethanol concentration of the final $\mathrm{PGE}_{2}$ solution was $\sim 2 \%$, a concentration previously shown to not affect the mechanical nociceptive threshold (Ferrari et al., 2016b).

alone 40 min after intradermal $\mathrm{PGE}_{2}$ administration, two-way ANOVA followed by Tukey's multiple-comparisons test). $n=6$ paws in each group. $\boldsymbol{C}, \boldsymbol{D}$, Male and female rats were treated intrathecally with ODN AS or MM $(120 \mu \mathrm{g} / 20 \mu \mathrm{l})$ for CD44 mRNA, daily for 3 consecutive days. 0 n the fourth day, $\sim 17$ $h$ after the last intrathecal administration of ODNs, PGE (100 ng/5 $\mu \mathrm{l}$ ) was injected intradermally on the dorsum of the hindpaw followed, 10 min later, by intradermal HMWH $(1 \mu \mathrm{g} / 5 \mu \mathrm{l})$ or vehicle $(5 \mu \mathrm{l})$. The mechanical nociceptive threshold was evaluated before and $40 \mathrm{~min}$ after intradermal $\mathrm{PGE}_{2}$. In male rats, the antihyperalgesic effect of HMWH on $\mathrm{PGE}_{2}$-induced hyperalgesia, was attenuated in the group treated with CD44 AS-ODN $\left(C ; F_{(2,10)}=51.53\right.$, \#\#\#p=0.0035, when the CD44 AS ODN-treated group was compared with the CD44 ODN MM-treated group; ${ }^{* *} p<0.0001$, when the CD44 AS-0DN-treated group was compared with the $\mathrm{PGE}_{2^{-}}$ treated group alone; ${ }^{* * *} p=0.0002$, when the CD44 MMODN-treated group was compared with the $P \mathrm{PE}_{2}$-treated group alone, 40 min after intradermal $\mathrm{PGE}_{2}$, two-way ANOVA followed by Tukey's multiple-comparisons test), while in female rats, CD44 AS-0DN completely reversed HMWH-

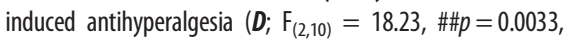
when the CD44 AS-ODN-treated group is compared with CD44 MM-ODN-treated group; ${ }^{* * *} p=0.0005$, when the CD44 MM-0DN-treated group was compared with the $\mathrm{PGE}_{2}-$ treated group, $40 \mathrm{~min}$ after intradermal $\mathrm{PGE}_{2}$, two-way ANOVA followed by Tukey's multiple-comparisons test). $n=6$ paws each group. $\boldsymbol{E}$, Western blot analysis of DRG extracts from male rats injected with $120 \mu \mathrm{g}$ of CD44 AS-0DN/day for three consecutive days revealed a significant decrease in their anti-CD44 immunoreactivity when compared with the extracts derived from CD44 MM-0DN- treated rats $(-24.8$ $+/-4.8 \%$, unpaired Student's $t$ test, $n=6, p<0.05)$. The calculated molecular weight of the main CD44 splice variant in rat tissue is $\sim 86 \mathrm{kDa}$ (according to $\mathrm{NCBI}$ database entry NP_037056). $\beta$-actin, which was used as a loading control, has a calculated molecular weight of $\sim 42 \mathrm{kDa}$ (according to UniProtKB database entry P60771). 

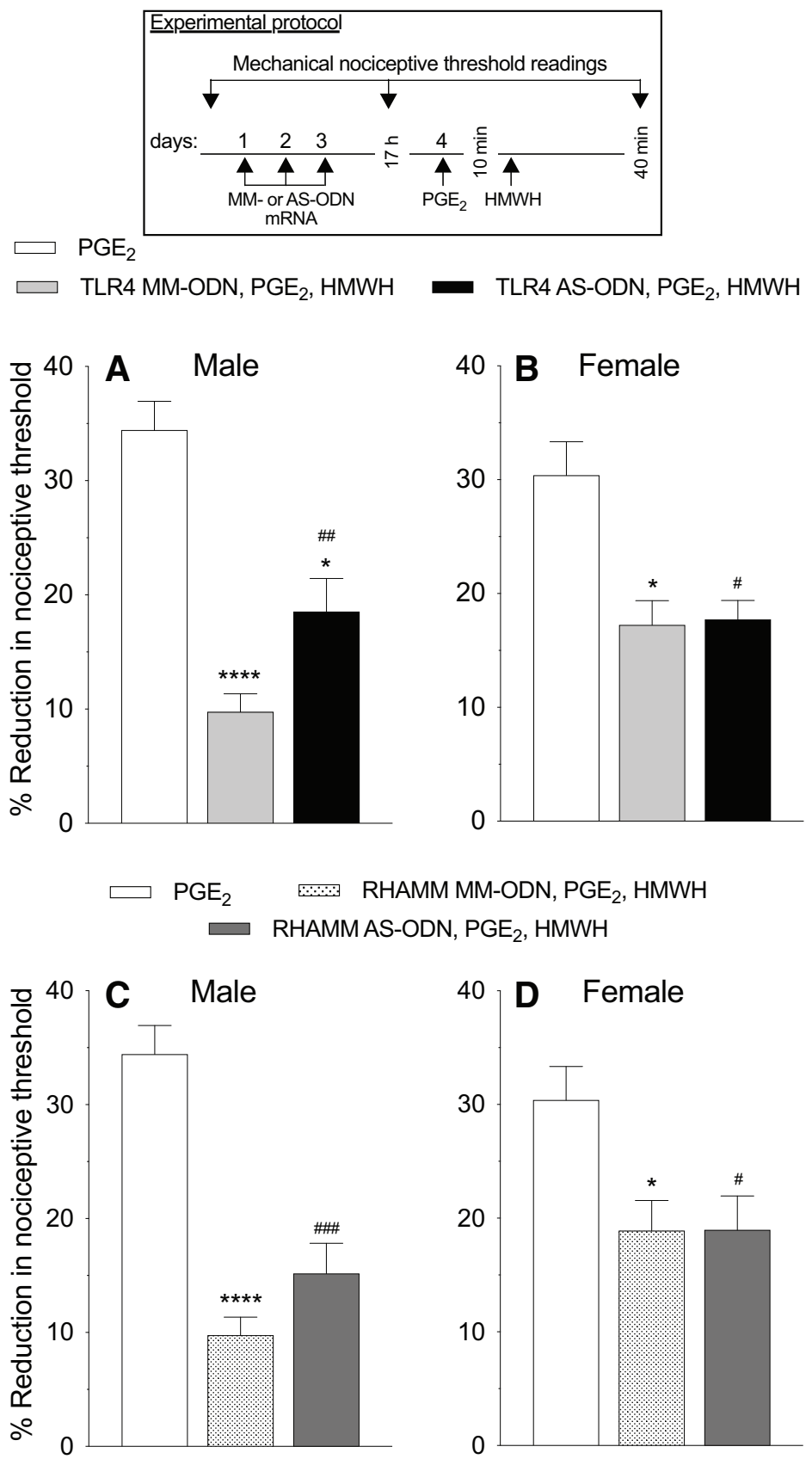

MM MM-ODN, $\mathrm{PGE}_{2}, \mathrm{HMWH}$
ODN, $\mathrm{PGE}_{2}, \mathrm{HMWH}$

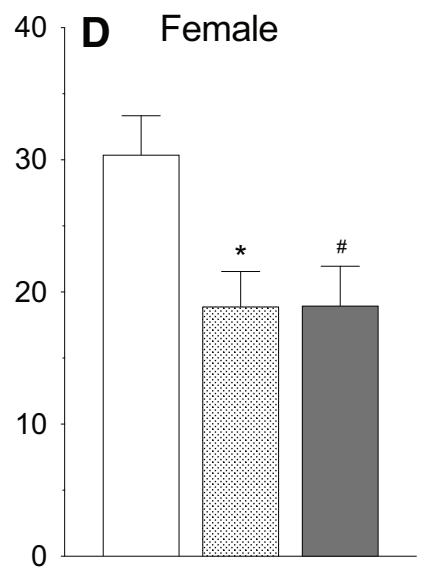

E
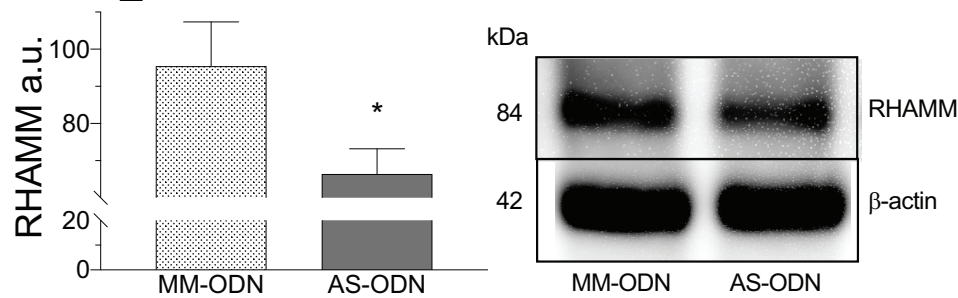

Figure 3. In male but not female rats, reversal of PGE hyperalgesia by HMWH was TLR4 dependent. $\boldsymbol{A}-\boldsymbol{D}$, Male and female rats were treated intrathecally with AS-ODN $(120 \mu \mathrm{g} / 20 \mu \mathrm{l})$ or MM-ODN $(120 \mu \mathrm{g} / 20 \mu \mathrm{l})$ for TLR4 $(\boldsymbol{A}, \boldsymbol{B})$ or RHAMM $(\boldsymbol{C}, \boldsymbol{D}) \mathrm{mRNA}$, once a day, for three consecutive days. On the fourth day, $\sim 17 \mathrm{~h}$ after the last intrathecal administration of $0 \mathrm{DNs}, \mathrm{PGE}_{2}(100 \mathrm{ng} /$ $5 \mu \mathrm{l})$ was injected intradermally on the dorsum of the hindpaw followed, 10 min later, by intradermal HMWH $(1 \mu \mathrm{g} / 5 \mu \mathrm{l})$. The mechanical nociceptive threshold is evaluated $40 \mathrm{~min}$ after intradermal $\mathrm{PGE}_{2}$. $\boldsymbol{A}, \boldsymbol{B}$, In male rats treated with TLR4 AS-ODN an attenuation in the antihyperalgesia induced by HMWH was observed $\left(\boldsymbol{A} ; \mathrm{F}_{(2,10)}=32.88\right.$, \#\#p $=0.0420$, when the TLR4 AS-ODNtreated group was compared with TLR4 MM-ODN-treated group; ${ }^{*} p<0.001$, when the TLR4 AS-ODN-treated group was compared with $\mathrm{PGE}_{2}$-treated group alone; ${ }^{* * *} p<0.0001$, when the TLR4 MM-ODN-treated group was compared with the $\mathrm{PGE}_{2}$-treated group alone, $40 \mathrm{~min}$ after intradermal $\mathrm{PGE}_{2}$, two-way ANOVA followed by Tukey's multiple comparison test);
Aliquots of HMWH, Y27632 and NSC23766, dissolved in distilled water to a concentration of $1 \mu \mathrm{g} / \mu \mathrm{l}$, were further diluted in $0.9 \% \mathrm{NaCl}$ to the concentration used in each experiment. Aliquots containing $1 \mu \mathrm{g} / \mu \mathrm{l}$ U0126, SU6656, U73122, LY249002, and wortmannin, dissolved in $100 \%$ dimethylsulfoxide (DMSO), were further diluted in $0.9 \%$ $\mathrm{NaCl}$ containing $10 \%$ DMSO to a concentration of $0.2 \mu \mathrm{g} / \mu \mathrm{l}$.

All drugs were administered intradermally, in a volume of $5 \mu \mathrm{l}$ (when injected alone) or $2 \mu \mathrm{l}$ each (when two or more drugs are injected), on the dorsum of the hindpaw, using a 30 gauge hypodermic needle attached to a $50 \mu$ l Hamilton syringe by a segment of PE-10 polyethylene tubing from Becton Dickinson. The administration of NSC23766, Y27632, U0126, SU6656, U73122, LY249002, and wortmannin was preceded by a hypotonic shock $(1 \mu \mathrm{l}$ of distilled water, separated by a bubble of air to avoid mixing in the same syringe) to transiently facilitate enhanced cell permeability to these agents, to get reagents inside the nerve terminal (Borle and Snowdowne, 1982; Burch and Axelrod, 1987).

Oligodeoxynucleotides antisense to CD44 receptor, Toll-like receptor 4, and RHAMM. The role of CD44, Toll-like receptor 4

$\leftarrow$

however, in female rats TLR4 AS-ODN did not affect the antihyperalgesia induced by HMWH $\left(\boldsymbol{B} ; \mathrm{F}_{(2,10)}=8.051\right.$, $\# p=0.0167$ and ${ }^{*} p=0.0136$, when the TLR4 AS-ODNand TLR4 MM-ODN-treated group was compared with the PGE 2 -treated group alone; $p=0.9907$, when TLR4 AS-ODN- and TLR4 MM-ODN-treated group are compared 40 min after intradermal $\mathrm{PGE}_{2}$, two-way ANOVA followed by Tukey's multiple-comparisons test). $n=6$ paws each group. $\boldsymbol{C}, \boldsymbol{D}$, In male $(\boldsymbol{C})$ and female $(\boldsymbol{D})$ rats treated with RHAMM AS-ODN, the antihyperalgesia induced by HMWH was not affected $\left(\boldsymbol{C}_{;} \mathrm{F}_{(2,10)}=43.23\right.$, $\# \# p=0.0001$ and ${ }^{* * *} p<0.0001$, when the RHAMM AS-ODN- and RHAMM MM-ODN-treated groups was compared with the $\mathrm{PGE}_{2}$-treated group alone; $p=0.1761$, when the RHAMM AS-ODN- and MM-ODNtreated groups was compared each other, $40 \mathrm{~min}$ after intradermal $\mathrm{PGE}_{2}$, two-way ANOVA followed by Tukey's multiple-comparisons test. $\left(D_{i} ; F_{(2,10)}=6.043\right.$, $\# p<0.0326$ and ${ }^{*} p=0.0317$, when the RHAMM AS ODN-treated and RHAMM MM ODN-treated groups was compared with the $\mathrm{PGE}_{2}$-treated group alone; $p=0.9998$, when the RHAMM AS-ODN- and MM ODNtreated groups were compared to each other, $40 \mathrm{~min}$ after intradermal $\mathrm{PGE}_{2}$ administration; two-way ANOVA followed by Tukey's multiple-comparisons test). $n=6$ paws in each group. $\boldsymbol{E}$, Western blot analysis of DRG extracts from male rats treated with $120 \mu \mathrm{g} / \mathrm{day}$ RHAMM AS ODN, for 3 consecutive days, reveals a significant decrease in RHAMM, compared with the extracts derived from RHAMM MM ODN-treated rats $(-30.4 \pm 4.6 \%$, unpaired Student's $t$ test, $n=6$, ${ }^{*} p=0.0239$ ). The calculated molecular weight of RHAMM is $\sim 82.4 \mathrm{kDa}$ (according to UniProtKB database entry Q9WUF7). $\beta$-actin, which was used as a loading control, has a calculated molecular weight of $\sim 42 \mathrm{kDa}$ (according to UniProtKB database entry P60771). 

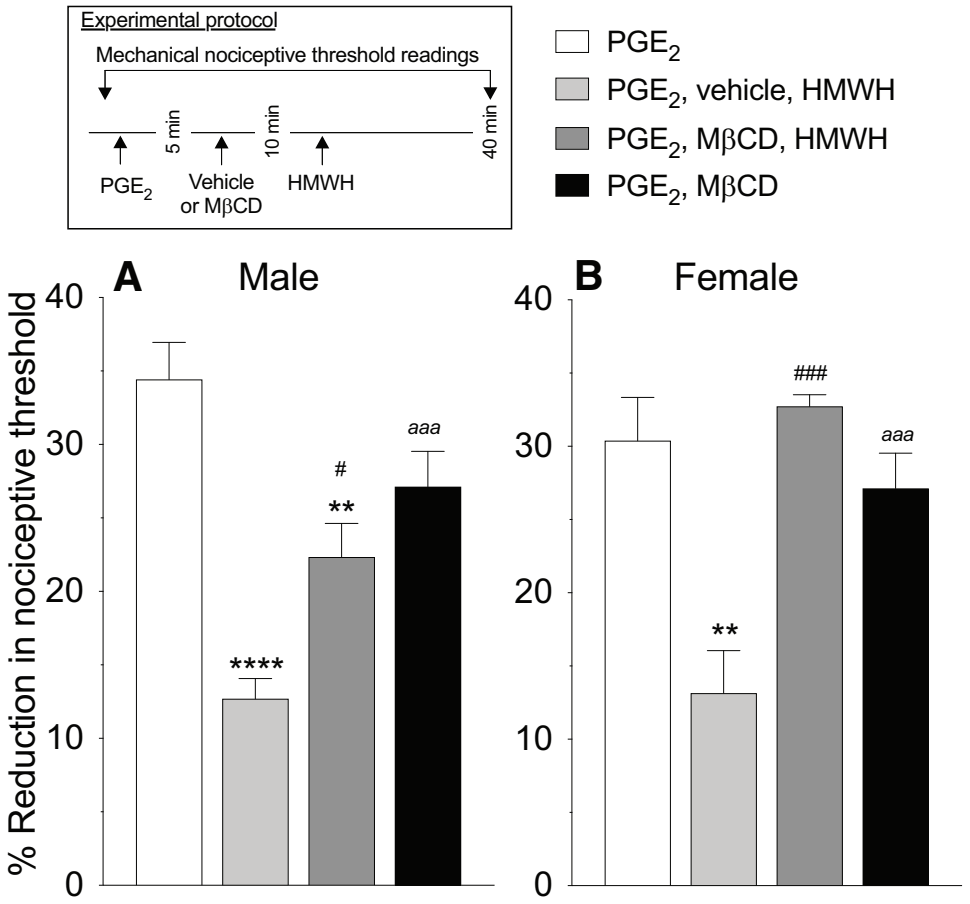

Figure 4. Lipid rafts are necessary for HMWH to induce antihyperalgesia. Male and female rats were treated intradermally with $P G E_{2}(100 \mathrm{ng} / 2 \mu \mathrm{l})$, followed 5 min later by a lipid raft disruptor $(M \beta C D, 1 \mu \mathrm{g} / 2 \mu \mathrm{l})$ or vehicle $(2 \mu \mathrm{l})$, also injected intradermally. Ten minutes after $\mathrm{PGE}_{2}$ administration, rats received intradermal HMWH $(1 \mu \mathrm{g} /$ $2 \mu \mathrm{l}$ ) and the mechanical nociceptive threshold was evaluated $40 \mathrm{~min}$ after intradermal $\mathrm{PGE}_{2}$ administration. $\boldsymbol{A}$, Male: $\mathrm{M} \beta C D$ significantly attenuated HMWH-induced antihyperalgesia $\left(F_{(3,15)}=22.60,{ }^{* *} p=0.0023\right.$, $\# p=0.0136$, when the $M \beta C D$ group plus the HMWH-treated group is compared with the $\mathrm{PGE}_{2}$-treated group and vehicle plus HMWH-treated group, respectively; ${ }^{* * *} p<0.0001$, when the vehicle plus HMWH-treated group was compared with the $P \mathrm{PE}_{2}$-treated group; aaap $=0.0004$, when the $\mathrm{M} \beta \mathrm{CD}$-treated group was compared with the $\mathrm{PGE}_{2}$-treated group, 40 min after intradermal $\mathrm{PGE}_{2}$ administration; two-way ANOVA followed by Tukey's multiple-comparisons test). $n=6$ paws in each group. $\boldsymbol{B}$, Female: $M \beta C D$ reverses HMWH-induced antihyperalgesia $\left(F_{(3,15)}=10.71\right.$, \#\#\#p =0.0006, when the $M \beta C D$ plus the HMWH-treated group was compared with the vehicle plus HMWH-treated group; ${ }^{* *} p=0.0019$, when the vehicle plus HMWH-treated group was compared with the $\mathrm{PGE}_{2}$-treated group; aaap $=0.0004$, when the $\mathrm{M} \beta C \mathrm{CD}$-treated group was compared with the vehicle plus HMWHtreated group, 40 min after intradermal $P_{G E}$, two-way ANOVA followed by Tukey's multiple-comparisons test). $n=6$ paws in each group.

(TLR4), and RHAMM in the antihyperalgesic effects of HMWH was assessed in rats treated intrathecally with oligodeoxynucleotide (ODN) antisense (AS) to the mRNA of each receptor. All the AS-ODN sequences were directed against a unique region of the rat mRNA sequence for that receptor.

AS-ODN sequences were as follows: CD44 AS-ODN mRNA: 5'GAA AAG GGT CGC GGG GG-3' (GenBank accession no. NM_ 012924.2); TLR4 AS-ODN mRNA: 5' -AGG AAG TGA GAG TGC CAA CC-3' (GenBank accession no. NM_019178.1); and RHAMM AS-ODN mRNA: 5' -ACC TGG AGA TGG AGC ACA AC-3' (GenBank accession no. NM_012964.2).

Mismatch (MM) ODN sequences correspond to the antisense sequence with mismatched bases (denoted by bold letters). MM_ODN sequences were as follows: CD44 MM-ODN mRNA: 5'-CCC CCG CGA CCC TTT TC-3'; TLR4 MM-ODN mRNA: 5'-ACG ATG CGA GAG AGT CAC CG-3'; and RHAMM MM-ODN mRNA: 5'-GCC TGA AGA TAG ACG ACA AT- $3^{\prime}$.

All ODNs were synthesized by Thermo Fisher Scientific; a decrease in TLR4 protein expression induced by the AS-ODN was recently demonstrated (Araldi et al., 2019). Before use, ODNs were reconstituted in nuclease-free $0.9 \% \mathrm{NaCl}$ and then administered intrathecally at a dose of $6 \mu \mathrm{g} / \mu \mathrm{l}$ in a volume of $20 \mu \mathrm{l}$ for 3 consecutive days (Araldi et al., 2019). As described previously (Alessandri-Haber et al., 2003), rats were anesthetized with isoflurane $\left(2.5 \%\right.$ in $\left.\mathrm{O}_{2}\right)$ and $120 \mu \mathrm{g}$ of ODN, in a volume of $20 \mu \mathrm{l}$, injected intrathecally using a syringe attached to a 29 gauge needle inserted into the subarachnoid space, between the L4 and L5 vertebrae.
The intrathecal site of injection was confirmed by a sudden flick of the tail of the rat, a reflex that is evoked by subarachnoid space access and bolus intrathecal injection (Mestre et al., 1994). Animals regained consciousness $\sim 2$ min after the injection. The use of AS-ODN administered intrathecally to attenuate the expression of proteins, essential for their role in nociceptor sensitization, is well supported by previous studies conducted by others (Song et al., 2009; Su et al., 2011; Quanhong et al., 2012; Sun et al., 2013; Oliveira-Fusaro et al., 2017), as well as by our group (Parada et al., 2003; Bogen et al., 2012; Alvarez et al., 2014; Ferrari et al., 2016a,b, 2018; Araldi et al., 2017, 2019).

SDS-PAGE and Western blotting. Analysis of the efficacy of the antisense treatment for CD44 and RHAMM expression in male rat lumbar dorsal root ganglia (DRGs) was done by SDS-PAGE and Western blotting. Rats were killed by exsanguination, while under isoflurane anesthesia, $24 \mathrm{~h}$ after the last injection of antisense (or mismatch) ODN against CD44 or RHAMM mRNA. L4 and L5 DRGs were then surgically removed and stored at $-80^{\circ} \mathrm{C}$ until further use. DRGs were transferred into homogenization buffer $(100 \mathrm{~mm} \mathrm{NaCl}, 1 \mathrm{~mm}$ EDTA, 2\% SDS, $50 \mathrm{~mm}$ Tris- $\mathrm{HCl}, \mathrm{pH}$ 7.4) that was supplemented with a protease inhibitor cocktail (Roche Diagnostics) and manually homogenized with a handheld plastic pestle. Proteins were solubilized by incubating the homogenized DRGs for $2 \mathrm{~h}$ at $37^{\circ} \mathrm{C}$, and homogenates were centrifuged at $1400 \mathrm{rpm}$ in an Eppendorf Thermomixer. Solubilized proteins were extracted from insoluble cell and tissue components by a $15 \mathrm{~min}$ centrifugation at 14,000 rpm in an Eppendorf tabletop centrifuge. The protein concentrations of all samples were determined using the Pierce Micro BCA Protein Assay Kit (Thermo Fisher Scientific) with bovine serum albu$\min$ (BSA) as the standard. Mixtures of $40 \mu \mathrm{g}$ of protein per sample were denatured by boiling in sample buffer [3\% SDS, $10 \%(\mathrm{v} / \mathrm{v})$ glycerol, $5 \%(\mathrm{v} / \mathrm{v}) \beta$-mercaptoethanol, $0.025 \mathrm{~mm}$ bromphenol blue, and $62.5 \mathrm{~mm}$ Tris- $\mathrm{HCl}$ at $\mathrm{pH} 6.8$ ] for $10 \mathrm{~min}$, and were electrophoresed on 4 $15 \%$ precast polyacrylamide gels (Bio-Rad) in $25 \mathrm{~mm}$ Tris containing $192 \mathrm{~mm}$ glycine and $0.1 \%$ SDS. Proteins were electrophoretically transferred to a nitrocellulose membrane using the semidry method [transfer time, $2 \mathrm{~h}$ at $60 \mathrm{~mA} / \mathrm{gel}$ with 47.9 mM Tris, $38.9 \mathrm{~mm}$ glycine, $0.038 \%$ SDS and $20 \%$ (v/v) methanol]. The nitrocellulose membranes were saturated by shaking in antibody dilution buffer [5\% BSA in Tris-buffered saline containing $0.1 \%$ Tween 20 , at $\mathrm{pH}$ 7.4 (TBST)] for $1 \mathrm{~h}$ at room temperature (RT; $20-23^{\circ} \mathrm{C}$ ), cut in half at $\sim 50 \mathrm{kDa}$ and probed with either a sheep polyclonal anti-CD44 antibody (1:500; catalog \#AF6577, R\&D Systems), a rabbit monoclonal antiRHAMM (1:500; catalog \#ab124729, Abcam), or a rabbit polyclonal anti$\beta$-actin (1:1000; catalog \#ab8227, Abcam) antibody in antibody dilution buffer at $4^{\circ} \mathrm{C}$ overnight. After rinsing with TBST (three times at RT, 15 min each), the RHAMM blot was probed with an biotinylated anti-rabbit antibody (1:2500; catalog \#111-065-003, Jackson ImmunoResearch) for $2 \mathrm{~h}$ at RT, whereas the CD44 blot was probed with a horseradish peroxidase-conjugated anti-sheep antibody (1:2500 in antibody dilution buffer; R\&D Systems) and the $\beta$-actin blots were probed with a horseradish peroxidase-conjugated anti-rabbit antibody (1:2500 in antibody dilution buffer; GE Healthcare LifeSciences) for $2 \mathrm{~h}$ at RT. All blotting membranes were rinsed with TBST (three times at RT, $15 \mathrm{~min}$ each), and the RHAMM blot was probed with a streptavidin-peroxidase polymer (1:5000; catalog \#S2438, Sigma-Aldrich) for $1.5 \mathrm{~h}$ while shaking at RT. After rinsing with TBST (three times at RT, 15 min each), the immunoreactivities of all blots were visualized using the Pierce West Femto Chemiluminescence Detection System (Thermo Fisher Scientific). Results were analyzed using computer-assisted densitometry, and levels of CD44 or RHAMM immunoreactivity 
were normalized with respect to the $\beta$-actin control levels in each sample. The percentage decrease in CD44 and RHAMM expression was calculated as follows: [(normalized density for AS/normalized density for MM $\times 100)-100$; Summer et al., 2008; Alvarez et al., 2017).

Culture of DRG neurons. Primary cultures of DRG neurons were made from adult male Sprague Dawley rats (weight, 220-235 g), as described previously (Ferrari et al., 2016b, 2018; Khomula et al., 2017, 2019; Araldi et al., 2019). In brief, under isoflurane anesthesia, rats were decapitated and the dorsum of the vertebral column surgically removed; L4 and L5 DRGs were rapidly extracted bilaterally, chilled, and desheathed in HBSS on ice. Ganglia were then treated with $0.25 \%$ collagenase type 4 (Worthington Biochemical) in HBSS for $18 \mathrm{~min}$ at $37^{\circ} \mathrm{C}$, and then treated with $0.25 \%$ trypsin (Worthington Biochemical) in Invitrogen calcium-free and magnesiumfree PBS (Thermo Fisher Scientific) for 6 min, followed by three washes and then trituration in Invitrogen Neurobasal-A medium (Thermo Fisher Scientific) to produce a single-cell suspension. This suspension was centrifuged at $1000 \mathrm{rpm}$ for $3 \mathrm{~min}$ and resuspended in Neurobasal-A medium supplemented with $50 \mathrm{ng} / \mathrm{ml}$ nerve growth factor, $100 \mathrm{U} / \mathrm{ml}$ penicillin/streptomycin, B-27, GlutaMAX, and 10\% FBS (Thermo Fisher Scientific). Cells were then plated on coverslips and incubated at $37^{\circ} \mathrm{C}$ in $3.5 \% \mathrm{CO}_{2}$ for at least 24 $\mathrm{h}$ before use in experiments.

In vitro patch-clamp electrophysiology. The bright-field imaging system consisted of an inverted microscope (Eclipse TE-200, Nikon Instruments) with an Andor Clara Interline CCD camera (Andor Technology), for high-resolution digital image acquisition, with MetaFluor software (Molecular Devices).

Cultured DRG neurons were used in in vitro electrophysiology experiments 24-96 h after DRG dissociation and plating neurons. While small-, medium-, and large-sized neurons were routinely observed in the same preparation, this study focused on cells with a soma diameter of $<30 \mu \mathrm{m}$ (small DRG neurons), predominantly representing C-type nociceptors (Harper and Lawson, 1985; Woolf and Ma, 2007). After mounting a coverslip with cells in the recording chamber, the culture medium was replaced with the external perfusion solution containing the following (in mM): 100 TEA-Cl, $50 \mathrm{NaCl}, 5$ $\mathrm{MgCl}_{2}, 0.1 \mathrm{CaCl}_{2}, 10$ glucose, and 10 HEPES, and adjusted to $\mathrm{pH} 7.4$ with TEA-OH; osmolarity is $310 \mathrm{mOsm} / \mathrm{kg}$ (Tuhkanen et al., 1998). Drugs were diluted to their final concentration in this solution. The volume of the recording chamber is $150 \mu \mathrm{l}$. The perfusion system is gravity driven at a flow rate of $0.5-1 \mathrm{ml} / \mathrm{min}$. All experiments were performed at RT.

Sodium currents in cultured DRG neurons were recorded in voltageclamp mode of whole-cell patch clamp. Recording electrodes were fabricated from borosilicate glass capillaries [inner diameter (i.d.), $0.84 \mathrm{~mm}$; outer diameter, $1.5 \mathrm{~mm}$; Warner Instruments] using a Flaming/Brown P-87 puller (Sutter Instrument). Recording electrodes were filled with a intracellular perfusion solution containing the following (in $\mathrm{mm}$ ): 100
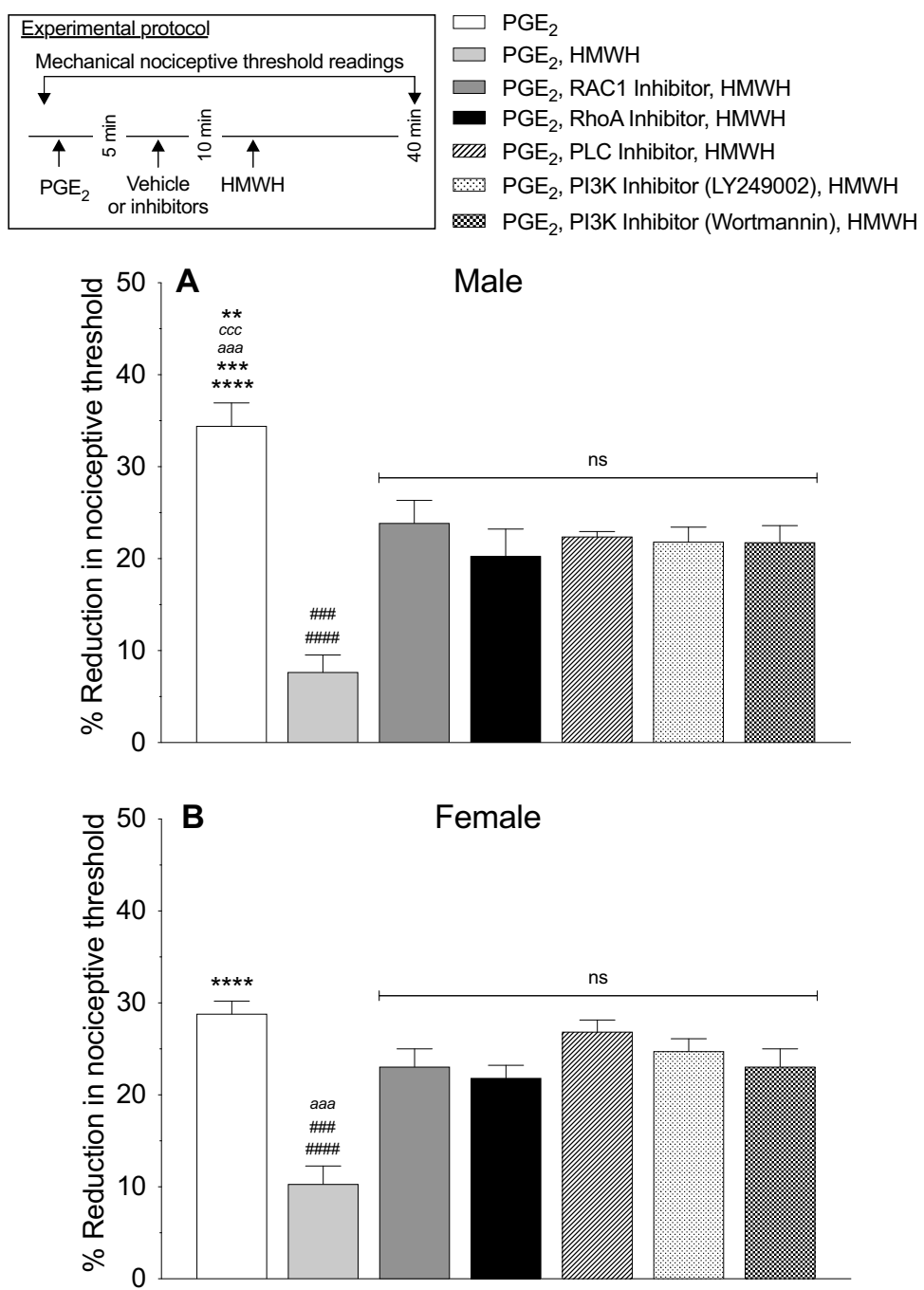

Figure 5. HMWH-induced antihyperalgesia is RhoA and Rac1 dependent. $\boldsymbol{A}, \boldsymbol{B}$, Male $(\boldsymbol{A})$ and female $(\boldsymbol{B})$ rats received $\mathrm{PGE}_{2}$ $(100 \mathrm{ng} / 2 \mu \mathrm{l})$ intradermally followed 5 min later by intradermal vehicle $(2 \mu \mathrm{l})$, Rac1 inhibitor (NSC23766 $1 \mu \mathrm{g} / 2 \mu \mathrm{l})$, RhoA inhibitor (Y27632 $1 \mu \mathrm{g} / 2 \mu \mathrm{l})$, PLC inhibitor (U73122, $1 \mu \mathrm{g} / 2 \mu \mathrm{l}$ ), or PI3K inhibitors (wortmannin or LY249002, $1 \mu \mathrm{g} / 2 \mu \mathrm{l} / \mathrm{each}$ ). Ten minutes after $\mathrm{PGE}_{2}$ administration, rats received intradermal HMWH $(1 \mu \mathrm{g} / 2 \mu \mathrm{l})$ and the mechanical nociceptive threshold was measured 40 min after intradermal $\mathrm{PGE}_{2}$. $\boldsymbol{A}$, The antihyperalgesic effect of $\mathrm{HMWH}_{\text {for }} \mathrm{PGE}_{2}$-induced hyperalgesia was attenuated by second messenger inhibitors of the CD44 signaling pathways in male rats $\left(F_{(6.30)}=19.69\right.$, \#\#\#p $<0.0001$, when the vehicle plus HMWH-treated group was compared with the NSC23766-, U73122-, LY249002-, and wortmannintreated groups, respectively; \#\#\# =0.0003, when the vehicle plus HMWH-treated group was compared with the Y27632treated group; ${ }^{* * *} p<0.0001$, when the $\mathrm{PGE}_{2}$-treated group was compared with the vehicle plus HMWH-treated and Y27632-treated groups, respectively; ${ }^{* *} p=0.0003$, aaap $<0.0004$, $c \subset c p=0.0003$, and ${ }^{* *} p=0.0034$, when the $\mathrm{PGE}_{2}$ treated group was compared with the wortmannin-, LY249002-, U73122-, and NSC23766-treated groups, respectively, 40 min after intradermal PGE 2 ; two-way ANOVA followed by Tukey's multiple-comparisons test). $n=6$ paws in each group. $\boldsymbol{B}$, In female rats, an attenuation of the antihyperalgesic effect of $\mathrm{HMWH}_{\text {for }} \mathrm{PGE}_{2}$-induced hyperalgesia was observed in all groups treated with the second messenger inhibitors $\left(F_{(6,30)}=12.69\right.$, \#\#\#\#p $<0.0001$, when the vehicle plus HMWH-treated group was compared with the LY249002- and U73122-treated groups, respectively; \#\#p $=0.0001$, when the vehicle plus HMWH-treated group was compared with the NSC23766 and wortmannin-treated groups, respectively; aaap $=0.0006$ when the vehicle plus HMWH-treated group was compared with Y27632-treated group; ${ }^{* * *} p<0.0001$, when the PGE $_{2}$-treated group is compared with the vehicle plus HMWH-treated group, 40 min after intradermal $\mathrm{PGE}_{2}$ administration; two-way ANOVA followed by Tukey's multiple-comparisons test). $n=6$ paws in each group.

CsCl, 40 TEA-Cl, $2 \mathrm{MgCl}_{2}, 1 \mathrm{CaCl}_{2}, 10$ EGTA, $5 \mathrm{MgATP}$, and $1 \mathrm{NaGTP}$, at pH7.2 (adjusted with Tris base) and osmolarity at $300 \mathrm{mOsm}$. Junction potential was not adjusted. Recording electrode resistance was $\sim 3.5 \mathrm{M} \Omega$. Series resistance was $<10 \mathrm{M} \Omega$ at the end of recordings and was not compensated. Recordings were made with an Axon MultiClamp $700 \mathrm{~B}$ Amplifier, filtered at $10 \mathrm{kHz}$, and sampled at $20 \mathrm{kHz}$ using an Axon Digidata 1550B digitizer controlled by pCLAMP 11 software (all from Molecular Devices). The holding membrane potential was set to $-70 \mathrm{mV}$. Tetrodotoxin-resistant (TTX-R) sodium current was induced 
in the presence of TTX (100 nM) by voltage step to $-10 \mathrm{mV}$ after $2 \mathrm{~s}$ conditioning at $-50 \mathrm{mV}$ (Gold et al., 1998).

Statistical analysis. In all behavioral experiments, the dependent variable was the percentage change from baseline mechanical paw withdrawal threshold. We used 114 (186 paws) male rats and 96 (150 paws) female rats in the behavioral tests. In the experiments using AS- or MMODN for CD44 (Fig. 2), TLR4, and RHAMM (Fig. 3), we evaluated both paws. Repeated-measures two-way ANOVA followed by Tukey's multiple-comparisons test or Student's $t$ test was used to analyze data.

Our Western blot results were presented as arbitrary units normalized to the reference protein $\beta$-actin. A total of 24 male rats ( 12 rats for CD44 AS-ODN and MM-ODN and 12 rats for RHAMM AS-ODN and MM-ODN mRNA) were used in Figures $2 E$ and $3 E$. Differences between groups treated with AS-ODN and MM-ODN for CD44 and RHAMM mRNA were analyzed using an unpaired Student's $t$ test.

In our electrophysiological experiments (see Fig. $7 B$ ), the dependent variable was the percentage reduction in peak sodium current induced by $\mathrm{HMWH}$, relative to a baseline measured after stimulation with $\mathrm{PGE}_{2}$, in the absence or presence of PI3K inhibitor. Differences between two groups were analyzed using a two-tailed unpaired Student's $t$ test (six neurons per group). A one-sample two-tailed Student's $t$ test was used to compare the magnitude of the reduction to a theoretical value of $0 \%$ (for no change) to examine whether the effect of $\mathrm{HMWH}$ was statistically significant.

Prism version 8.0 (GraphPad Software) was used for the graphics and to perform statistical analyses; $p<0.05$ was considered statistically significant. Data are presented as the mean \pm SEM.

\section{Results}

\section{HMWH attenuates $\mathrm{PGE}_{2}$ hyperalgesia}

We previously demonstrated that HMWH attenuates LMWH in male rats (Ferrari et al., 2016a). Here we first compare the effect of $\mathrm{HMWH}$ on $\mathrm{PGE}_{2}$ hyperalgesia, in both sexes, and established its dose dependence. $\mathrm{PGE}_{2}$ (100 ng) was administered intradermally, on the dorsum of the hindpaw, followed $10 \mathrm{~min}$ later by HMWH $(1 \mu \mathrm{g})$, injected at the same site. The mechanical nociceptive threshold was evaluated 40 min after intradermal $\mathrm{PGE}_{2}$ administered. Hyperalgesia induced by $\mathrm{PGE}_{2}$ was significantly attenuated by $\mathrm{HMWH}$, in both male and female rats (Fig. $1 A$ : $t_{(10)}=5.676, p=0.0002$; Fig. $1 B: t_{(10)}=7.860, p<0.0001$, when the vehicle-treated and HMWH-treated groups are compared 40 min after intradermal $\mathrm{PGE}_{2}$, unpaired Student's $t$ test). To exclude an independent effect on nociceptive threshold, we evaluated the effect of HMWH on baseline nociceptive threshold, in male rats. Three different doses of $\operatorname{HMWH}(0.1,1$, and $10 \mu \mathrm{g})$ were administered intradermally on the dorsum of the hindpaw, in a volume of $5 \mu \mathrm{l}$, and mechanical nociceptive threshold evaluated $0.5,1,2,4,8$, and $24 \mathrm{~h}$ later. None of these doses of HMWH affected the nociceptive threshold (Fig. 1C: $F_{(15,100)}=$ $1.168, p=0.3088$, when the three different doses of HMWH are compared with the vehicle-treated group, $30 \mathrm{~min}$ after their injection; two-way ANOVA multiple-comparisons test). For subsequent experiments, we used the middle dose, $1 \mu \mathrm{g}$, which we have previously shown to produce a robust antihyperalgesia (Ferrari et al., 2018).

\section{HMWH acts at CD44 to produce antihyperalgesia}

To test the hypothesis that HMWH acts at CD44 to produce antihyperalgesia, rats received an intradermal injection of $\mathrm{PGE}_{2}$ (100 ng) followed by injection of a CD44 antagonist (A5G27, $1 \mu \mathrm{g})$ at the same site, and then 5 min later HMWH $(1 \mu \mathrm{g})$ was injected at the same site. Male rats receiving the CD44 antagonist showed attenuation of $\mathrm{HMWH}$-induced anti-PGE 2 hyperalgesia (Fig. $2 A ; F_{(2,10)}=19.85, p=0.0344$, when the A5G27+HMWHtreated group is compared with vehicle $+\mathrm{HMWH}$-treated group,
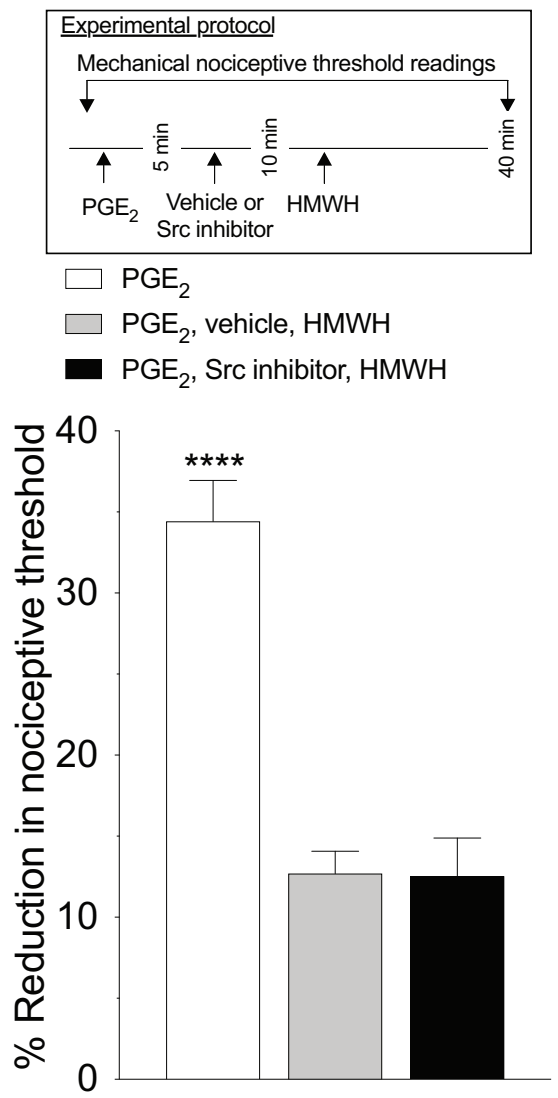

Figure 6. HMWH-induced antihyperalgesia is not dependent on Src. Male rats received an intradermal injection of $\mathrm{PGE}_{2}(100 \mathrm{ng} / 2 \mu \mathrm{l})$, followed 5 min later by the Src inhibitor (SU6656, $1 \mu \mathrm{g} / 2 \mu \mathrm{l})$ or vehicle $(2 \mu \mathrm{l})$, injected at the same site. Ten minutes after PGE 2 administration, rats received intradermal HMWH $(1 \mu \mathrm{g} / 2 \mu \mathrm{l})$ and the mechanical nociceptive threshold was evaluated 40 min after intradermal $\mathrm{PGE}_{2}$. Treatment with the Src inhibitor SU6656 did not affect the antihyperalgesia induced by $\operatorname{HMWH}\left(F_{(2,10)}=47.74\right.$, ${ }^{* * * *} p<0.0001$, when the $\mathrm{PGE}_{2}$-treated group was compared with the vehicle plus HMWHtreated and SU6656-treated groups; $p=0.9979$, when the SU6656-treated group is compared with the vehicle plus HMWH-treated group 40 min after intradermal PGE ANOVA followed by Tukey's multiple-comparisons test). $n=6$ paws in each group.

40 min after intradermal $\mathrm{PGE}_{2}$; two-way ANOVA multiple-comparisons test). In female rats, the CD44 antagonist completely reversed HMWH-induced antihyperalgesia (Fig. $2 B ; F_{(2,10)}=$ 11.28, $p=0.0127$, when the A5G27+HMWH-treated group is compared with the vehicle+HMWH-treated group, $40 \mathrm{~min}$ after intradermal $\mathrm{PGE}_{2}$; two-way ANOVA multiple-comparisons test).

Additional groups of male and female rats received intrathecal AS-ODN for CD44 mRNA, daily for 3 consecutive days, as previously described (Ferrari et al., 2018). On the fourth day, $\sim 17 \mathrm{~h}$ after the last ODN administration, $\mathrm{PGE}_{2}(100 \mathrm{ng})$ was injected intradermally on the dorsum of the hindpaw, followed 10 min later by HMWH $(1 \mu \mathrm{g})$ at the same site. In male rats that received CD44 AS-ODN, attenuation of HMWH-induced antihyperalgesia was observed (Fig. $2 C ; F_{(2,10)}=51.53, p=0.0035$, when the CD44 AS-ODN-treated group is compared with the CD44 MM-ODN-treated group, 40 min after intradermal $\mathrm{PGE}_{2}$, two-way ANOVA multiple-comparisons test), while in female rats, it was completely reversed (Fig. $2 D ; F_{(2,10)}=18.23$, $p=0.0033$, when the CD44 AS-ODN-treated and MM-ODNtreated groups are compared $40 \mathrm{~min}$ after intradermal $\mathrm{PGE}_{2}$; two-way ANOVA multiple-comparisons test).

Since HA also signals via RHAMM and TLR4 (Lennon and Singleton, 2011), we next evaluated whether the inhibition of 
$\mathrm{PGE}_{2}$ hyperalgesia by $\mathrm{HMWH}$ is RHAMM or TLR4 dependent. Rats received intrathecal administration of AS-ODN targeting RHAMM or TLR4 mRNA (Fig. 3). On the fourth day, $\sim 17 \mathrm{~h}$ after the last intrathecal administration of ODN, $\mathrm{PGE}_{2}(100 \mathrm{ng})$ was injected intradermally on the dorsum of the hindpaw, followed 10 min later by HMWH $(1 \mu \mathrm{g})$ injected at the same site. In the group of male rats treated with TLR4 AS-ODN, an attenuation of $\mathrm{HMWH}$-induced antihyperalgesia was observed (Fig. $3 A ; F_{(2,10)}=32.88$, $p=0.0420$, when the TLR4 AS-ODN-treated group is compared with TLR4 MM-ODNtreated group, $40 \mathrm{~min}$ after intradermal $\mathrm{PGE}_{2}$; two-way ANOVA multiple-comparisons test). However, intrathecal treatment with TLR4 AS-ODN did not affect HMWHinduced antihyperalgesia in female rats (Fig. $3 B ; F_{(2,10)}=8.051, p=0.9907$, when the TLR4 AS-ODN-treated and MM-ODN-treated groups are compared $40 \mathrm{~min}$ after intradermal $\mathrm{PGE}_{2}$ administration; two-way ANOVA multiple-comparisons test). RHAMM AS-ODN did not affect the antihyperalgesic effect induced by $\mathrm{HMWH}$ in male or female rats (Fig. $3 C$ : $F_{(2,10)}=43.23 p=0.1761$, when the RHAMM AS-ODN-treated group was compared with MM-ODN-treated group, $40 \mathrm{~min}$ after intradermal $\mathrm{PGE}_{2}$; two-way ANOVA multiple-comparisons test; Fig. 3D: $F_{(2,10)}=$ $6.043, p=0.9998$, when the RHAMM ASODN-treated and MM-ODN-treated groups are compared $40 \mathrm{~min}$ after intradermal $\mathrm{PGE}_{2}$; two-way ANOVA multiple-comparisons test).

Previously, we demonstrated that TLR4 AS-ODN mRNA, administered intrathecally, reduced the expression of TLR4 in DRGs (Araldi et al., 2019). In the present study, we demonstrate knockdown of the expression of CD44 in DRGs by Western blot (pooled L4 and L5 ganglia) in ODNtreated male rats (Fig. 2E), in which we observed a $24.8 \pm 4.8 \%$ (arbitrary units normalized to the reference protein; unpaired Student's $t$ test, $p=0.0005$, when the CD44 AS-ODN-treated and MM-ODN-treated groups are compared; unpaired Student's $t$ test) decrease in the expression of CD44 in DRGs from AS-ODN-treated rats, when compared with MM-ODN controls. Evidence for AS-ODN-induced reduction of RHAMM expression in DRGs can be seen in Western blots (pooled L4 and L5 ganglia) from ODN-treated male rats (Fig. $3 E$ ), in which we observe a $30.4 \pm 4.6 \%$ (arbitrary units normalized to the reference protein; $p=0.0306$, when the RHAMM AS-ODN-treated and MM-ODN-treated groups are compared; unpaired Student's $t$ test) decrease in the expression of RHAMM, in AS-ODNtreated rats, compared with the MM-ODN control.

Role of lipid rafts in $\mathrm{HMWH}$-induced antihyperalgesia Since signaling through CD44 and other HA receptors is lipid raft dependent, we investigated whether disrupting lipid rafts
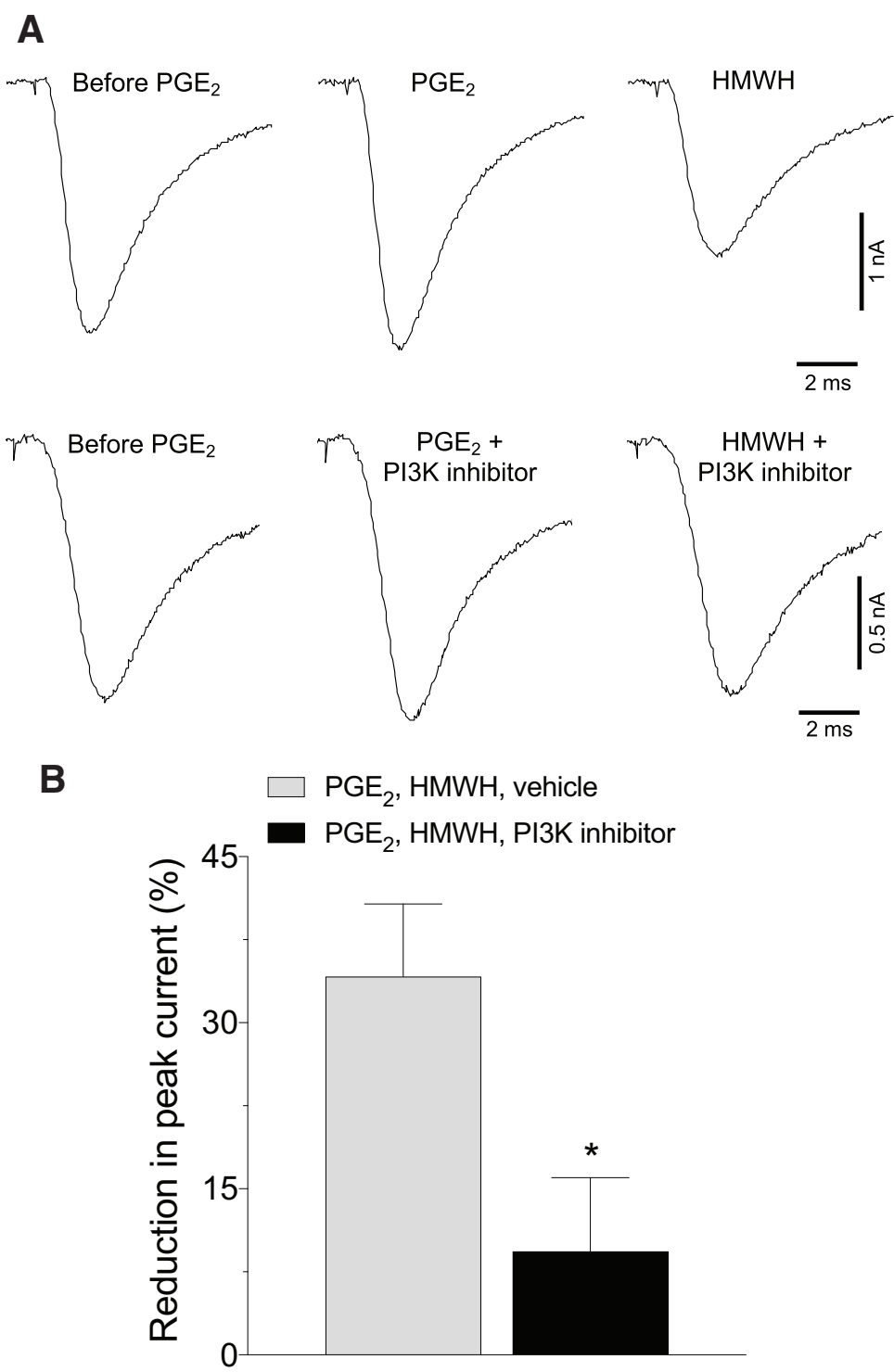

Figure 7. Inhibition of PI3K reverses attenuation of $\mathrm{PGE}_{2}$-sensitized TTX-R sodium current induced by HMWH. Small DRG neurons from male rats were held at $-70 \mathrm{mV}$ in voltage-clamp mode of whole-cell patch clamp. TTX-R sodium current was induced in the presence of TTX (100 nM) by voltage step to $-10 \mathrm{mV}$ after $2 \mathrm{~s}$ conditioning at $-50 \mathrm{mV}$. $\boldsymbol{A}$, Illustrative traces depicting TTX-R sodium current as follows(left to right): before administration of $\mathrm{PGE}_{2}(1 \mu \mathrm{M}), 5$ later, and 5 min after administration of HMWH $(200 \mu \mathrm{g} / \mathrm{ml})$ either alone (top) or with the addition of the PI3K inhibitor (LY249002, $50 \mu \mathrm{m}$; bottom). Note the substantial reduction in TTX-R sodium current induced by HMWH (top) and attenuation of this effect, when PI3K inhibitor was added (bottom). $\boldsymbol{B}$, Pooled magnitudes of reduction in peak TTX-R sodium current $5 \mathrm{~min}$ after bath application of HMWH, relative to a baseline measured before this application ( $5 \mathrm{~min}$ after stimulation with $1 \mu \mathrm{M} \mathrm{PGE}_{2}$ ), in the absence (white bar) or presence (black bar) of PI3K inhibitor (LY249002, $50 \mu \mathrm{m}$ ). Inhibition of TTX-R sodium current by HMWH was attenuated by LY249002 (two-tailed unpaired Student's $t$ test: $t_{(10)}=2.7,{ }^{*} p=$ 0.024). $n=6$ neurons/group.

attenuates HMWH-induced antihyperalgesia. Male and female rats were treated intradermally with $\mathrm{PGE}_{2}(100 \mathrm{ng})$, followed 5 min later by $\mathrm{M} \beta \mathrm{CD}$ (a lipid raft disruptor; $1 \mu \mathrm{g}$ ), and then a further $5 \mathrm{~min}$ later, $\mathrm{HMWH}$ was injected at the same site. We found that in male rats $\mathrm{M} \beta \mathrm{CD}$ attenuates $\mathrm{HMWH}$-induced antihyperalgesia (Fig. $4 A ; F_{(3,15)}=22.60, p=0.0136$, when the $\mathrm{M} \beta \mathrm{CD}+\mathrm{HMWH}$-treated group was compared with the vehicle + HMWH-treated group $40 \mathrm{~min}$ after intradermal $\mathrm{PGE}_{2}$; two-way ANOVA multiple-comparisons test), while in female rats it was completely reversed (Fig. $4 B ; F_{(3,15)}=10.71, p=0.0006$, when the $\mathrm{M} \beta \mathrm{CD}+\mathrm{HMWH}$-treated group was compared with the 
vehicle $+\mathrm{HMWH}$-treated group $40 \mathrm{~min}$ after intradermal $\mathrm{PGE}_{2}$; two-way ANOVA multiple-comparisons test).

\section{Second messengers mediating HMWH-induced antihyperalgesia}

To evaluate for second messengers that mediate HMWHinduced antihyperalgesia, we screened second messengers for receptors implicated in HMWH signaling. To test the hypothesis that HMWH signals through RhoA or Racl to induce antihyperalgesia, male and female rats were treated intradermally with $\mathrm{PGE}_{2}$ followed 5 min later by a Rac1 (NSC23766, $1 \mu \mathrm{g}$ ) or RhoA $(\mathrm{Y} 27632,1 \mu \mathrm{g})$ inhibitor and then, $5 \mathrm{~min}$ later, by HMWH $(1 \mu \mathrm{g})$. All drugs were injected intradermally on the dorsum of the hindpaw. Male and female rats treated with NSC23766 or Y27632 show an attenuation of HMWH-induced antihyperalgesia (Fig. 5A: $F_{(6,30)}=19.69, p<0.0001$, when the NSC23766 + HWMH-treated group is compared with the vehicle $+\mathrm{HMWH}$-treated group; $p=0.0003$, when the Y23766 $+\mathrm{HWMH}$-treated group is compared with the vehicle+HMWH-treated group 40 min after intradermal $\mathrm{PGE}_{2}$ administration; two-way ANOVA multiple-comparisons test; Fig. $5 B: F_{(6,30)}=12.69, p=0.0001$, when the NSC23766+HWMHtreated group is compared with the vehicle+HMWH-treated group; $p=0.0006$, when the Y23766 $+\mathrm{HWMH}$-treated group is compared with the vehicle+HMWH-treated group $40 \mathrm{~min}$ after intradermal $\mathrm{PGE}_{2}$; two-way ANOVA multiple-comparisons test).

RhoA and Rac1, in turn, activate ROK and PKN (fatty acidactivated serine/threonine kinase), respectively, which phosphorylate PLC $\varepsilon$ and PLC $\gamma 1$ (Bourguignon et al., 2014). To determine whether PLC is involved in $\mathrm{HMWH}$-induced anti-PGE $\mathrm{PG}_{2}$-induced hyperalgesia, we treated male and female rats with $\mathrm{PGE}_{2}$ intradermally, followed 5 min later by a PLC inhibitor (U73122, $1 \mu \mathrm{g}$ ), and then 5 min later by $\mathrm{HMWH}$, also injected intradermally. In both male and female rats treated with U73122, HMWH-induced antihyperalgesia was attenuated (Fig. $5 A: F_{(6,30)}=19.69, p<0.0001$, when the U73122+HWMH-treated group is compared with the vehicle+HMWH-treated group $40 \mathrm{~min}$ after intradermal $\mathrm{PGE}_{2}$; two-way ANOVA multiple-comparisons test; Fig. 5B: $F_{(6,30)}=$ 12.69, $p=0.0001$, when the U73122 $+\mathrm{HWMH}$-treated group is compared with vehicle+HMWH-treated group 40 min after intradermal $\mathrm{PGE}_{2}$; two-way ANOVA multiple-comparisons test). The role of PI3K was also investigated, since RhoA activates ROK, which, in turn phosphorylates PLC $\varepsilon$ and promotes the membrane localization of Gab-1 (scaffold protein), to activate PI3K (Bourguignon et al., 2014). Rats received $\mathrm{PGE}_{2}$ intradermally, followed $5 \mathrm{~min}$ later by one of two PI3K inhibitors (wortmannin $1 \mu \mathrm{g}$ or LY249002 $1 \mu \mathrm{g}$ ), and then $5 \mathrm{~min}$ later by HMWH injected intradermally. In both male and female rats treated with either PI3K inhibitor, the antihyperalgesic effect induced by HMWH was attenuated (Fig. $5 A: F_{(6,30)}=19.69, p<0.0001$, when the LY249002treated and wortmannin $+\mathrm{HWMH}$-treated groups are compared with the vehicle+HMWH-treated group, respectively, 40 min after intradermal $\mathrm{PGE}_{2}$; two-way ANOVA multiple-comparisons test; Fig. 5B: $F_{(6,30)}=19.69, p<0.0001$; and $p=0.0001$ when the LY249002-treated and wortmannin + HWMH-treated groups are compared with the vehicle+HMWH-treated group, respectively, 40 min after intradermal $\mathrm{PGE}_{2}$; two-way ANOVA multiple-comparisons test).

Finally, since Src is involved in LMWH-induced hyperalgesia (Ferrari et al., 2016a), we tested whether HMWH also signals through Src. Male rats were treated intradermally with $\mathrm{PGE}_{2}$ followed $5 \mathrm{~min}$ later by an Src inhibitor (SU6656, $1 \mu \mathrm{g}$ ), and then 5 min later by HMWH. The Src inhibitor did not affect HMWHinduced antihyperalgesia (Fig. $6 ; F_{(2,10)}=47.74, p=0.9979$, when

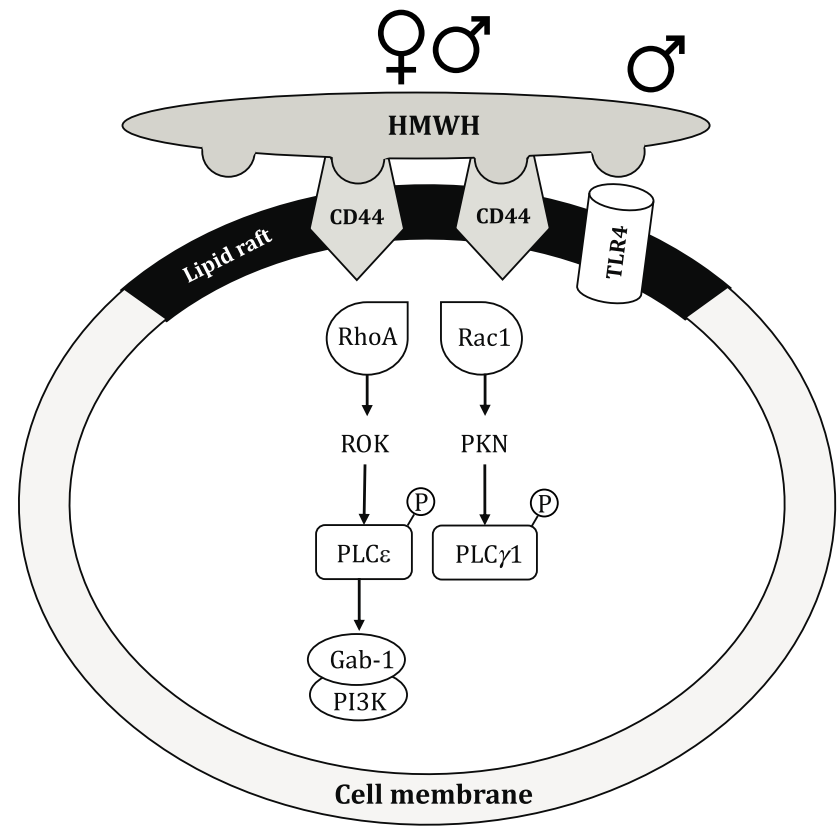

Figure 8. Schematic representation of potential signaling pathways involved in HMWHinduced antihyperalgesia. In male and female rats, HMWH binds to CD44 to induce its clustering in cell membrane lipid rafts and initiate signaling in downstream second messenger pathways. After HMWH binds to CD44, it can signal via RhoA and Rac1, which, in turn, activate ROK and PKN, respectively, leading to phosphorylation of $\operatorname{PLC} \varepsilon$ and $\operatorname{PLC} \gamma 1$, respectively. Binding of HMWH to CD44 also stimulates RhoA, which activates ROK to phosphorylate $\mathrm{PLC} \varepsilon$, increasing serine/threonine phosphorylation of the adaptor protein Gab-1 and leading to activation of PI3K. In male rats, HMWH also signals via TLR4.

the SU6656+HWMH-treated group is compared with the vehicle + HMWH-treated group 40 min after intradermal $\mathrm{PGE}_{2}$; two-way ANOVA multiple-comparisons test).

Of note, all the inhibitors tested in this experiment were also injected intradermally, in groups pretreated 5 min before with intradermal $\mathrm{PGE}_{2}(100 \mathrm{ng} / 2 \mu \mathrm{l})$. None of the inhibitors affected $\mathrm{PGE}_{2}$-induced hyperalgesia, measured $40 \mathrm{~min}$ after intradermal $\mathrm{PGE}_{2}$ (data not shown).

\section{HMWH induces PI3K-dependent attenuation of $\mathrm{PGE}_{2}$ -} sensitized TTX-resistant sodium current in vitro

Potentiation of TTX-resistant voltage-gated sodium current (referred to here as TTX-R sodium current) contributes to a sensitizing effect of $\mathrm{PGE}_{2}$, reflected as a reduction in rheobase and in onset latency to action potential (Gold et al., 1998). We have recently shown that $\mathrm{HMWH}$ reverses $\mathrm{PGE}_{2}$-induced reduction in rheobase and action potential onset latency in cultured small DRG neurons (Ferrari et al., 2018). In the present experiments, we examined whether HMWH attenuates TTX-R sodium current in small DRG neurons from male rats sensitized by $\mathrm{PGE}_{2}$ (England et al., 1996) and whether this is PI3K dependent. The peak magnitude of TTX-R sodium current recorded 5 min after administration of $\mathrm{PGE}_{2}(1 \mu \mathrm{M})$ was considered as the baseline. HMWH $(200 \mu \mathrm{g} / \mathrm{ml})$ was then administered and 5 min later peak TTX-R sodium current measured, and its change relative to baseline analyzed (Fig. 7). HMWH significantly attenuated TTX-R sodium current, on average by $34 \pm 7 \% \quad(n=6$; compared with theoretical value of $0 \%$ with one-sample two-tailed Student's $t$ test: $\left.t_{(5)}=5.2, p=0.003\right)$, supporting the suggestion that HMWH attenuates TTX-R sodium current, contributing to the antihyperalgesic effect of HMWH in vivo. 
In our behavioral experiments, we found that the antihyperalgesic effect of HMWH is PI3K dependent (reversed to a similar extent by two PI3K inhibitors, LY249002 and wortmannin). Therefore, we next examined whether the prototypical PI3K inhibitor LY249002 can also reduce the attenuating effect of $\mathrm{HMWH}$ on $\mathrm{PGE}_{2}$-sensitized TTX-R sodium current. In a separate group of neurons, LY249002 $(50 \mu \mathrm{M})$ was administered along with $\mathrm{PGE}_{2}(1 \mu \mathrm{M})$ and then $\mathrm{HMWH}$ in the same above-mentioned protocol. We found that in the presence of LY249002, HMWH did not significantly attenuate TTX-R sodium current (the average reduction was only $9 \pm 7 \%, n=6$; compared with $0 \%$ with the one-sample two-tailed Student's $t$ test: $t_{(5)}=1.4$, $p=0.22$ ). Attenuation of the effect of HMWH on TTX-R sodium current was significant (Fig. 7 ; eliminated $\sim 75 \%$ of the initial effect; two-tailed unpaired Student's $t$ test: $t_{(10)}=2.7, p=0.024$; $n=6$ neurons/group).

\section{Discussion}

The fact that the receptor antagonist and AS-ODN for CD44 both inhibit HMWH-induced antihyperalgesia supports the suggestion that $\mathrm{HMWH}$ acts at $\mathrm{CD} 44$, present in nociceptors, to produce antihyperalgesia. That HMWH does not change mechanical nociceptive threshold in naive control rats, supports the suggestion that HMWH acts to reverse nociceptor sensitization. HA can also interact with other receptors, including TLR4 and RHAMM (Vigetti et al., 2014), and we found that TLR4 ASODN attenuated HMWH-induced antihyperalgesia only in male rats; and RHAMM AS-ODN did not affect HMWH-induced antihyperalgesia in either sex. The fact that in male, but not female, rats, HMWH-induced antihyperalgesia is partially dependent on TLR4 could be related to the ability of CD44 to act as a negative regulator of TLR4-mediated inflammation (Liang et al., 2007; Kawana et al., 2008); and that estrogen reduces TLR4 mRNA and protein by activation of the G-protein-coupled estrogen receptor (GPR30), which is significantly increased after ischemic injury (Zhang et al., 2018). Importantly, our results support the suggestion that CD44 is the major HA receptor at which HMWH acts to produce antihyperalgesia in females, while CD44 and TLR4 contribute to HMWH antihyperalgesia in males.

Since HMWH induces CD44 clustering, in lipid rafts, to regulate signaling (Donatello et al., 2012; Qian et al., 2012), we investigated whether disruption of lipid rafts could attenuate HMWH-induced antihyperalgesia. The lipid raft disruptor, $\mathrm{M} \beta \mathrm{CD}$, which alone does not affect $\mathrm{PGE}_{2}$-induced hyperalgesia, attenuates $\mathrm{HMWH}$-induced antihyperalgesia. Our observation for dependence on lipid rafts for HMWH antihyperalgesia may be because of the requirement of CD44 clustering for $\mathrm{HMWH}$, but not LMWH signaling (Lee et al., 2008; Wu et al., 2018). We cannot exclude the influence of other receptors, such as TLR4 in male rats, in the effect of $\mathrm{M} \beta \mathrm{CD}$, since the $\mathrm{M} \beta \mathrm{CD}$ experiment was only meant to demonstrate the requirement of lipid rafts for $\mathrm{HMWH}$-induced antihyperalgesia.

CD44 can also signal via RhoA and Rac1 (Bourguignon et al., 2014). Rats that received a Racl or RhoA inhibitor, demonstrated attenuation of HMWH-induced antihyperalgesia. RhoA and Racl activate ROK and PKN, respectively, which in turn phosphorylate PLC $\varepsilon$ and PLC $\gamma 1$ (Bourguignon et al., 2014). We found that a PLC inhibitor also attenuated HMWH-induced antihyperalgesia. Furthermore, RhoA activates ROK to phosphorylate PLC $\varepsilon$ and promote the membrane localization of Gab-1, which, in turn, activates PI3K (Bourguignon et al., 2014). We found that two PI3K inhibitors attenuated HMWH-induced antihyperalgesia. We also observed that the administration of HMWH significantly attenuated $\mathrm{PGE}_{2}$-sensitized TTX-R sodium current, in small-diameter DRG neurons. This effect was markedly reduced $(\sim 75 \%)$ by a PIK3 inhibitor. These in vitro findings are in agreement with the results of our behavioral studies demonstrating $\mathrm{PI} 3 \mathrm{~K}$-dependent reversal of $\mathrm{PGE}_{2}$-induced mechanical hyperalgesia following the administration of HMWH. Of note, PI3K inhibitors did not affect the mechanical nociceptive threshold or $\mathrm{PGE}_{2}$-induced hyperalgesia by themselves, excluding an independent role in the setting of nociceptive threshold or reversing hyperalgesia.

We cannot, at present, provide a mechanistic explanation of how PI3K can be both pronociceptive and antinociceptive (e.g., acting in different nociceptors or by a switch in downstream signaling pathways). Of note, however, there are several isoforms of $\mathrm{PI} 3 \mathrm{~K}$, including different isoforms present in DRG (PI3K $\alpha$, $\mathrm{PI} 3 \mathrm{~K} \beta, \mathrm{PI} 3 \mathrm{~K} \delta$, and $\mathrm{PI} 3 \mathrm{~K} \gamma$; Leinders et al., 2014). And, different PI3K isoforms can execute distinct, and sometimes opposing, functions (Vanhaesebroeck et al., 2010). A second paradox relates to the activation of TLR4 (e.g., by lipopolysaccharide) to produce hyperalgesia (Wang et al., 2016), while we observed TLR4 mediating HMWH-induced antihyperalgesia in male rats. The ability of TLR4 AS-ODN to attenuate HMWH-induced antihyperalgesia, in males, could be because of a physical association between CD44 and TLR4 (Taylor et al., 2007). And, knocking down TLR4 expression may also decrease expression or functionality of CD44; the expression of CD44 in mesenchymal stem cells is lower in TLR4 knock-out mice (Wang et al., 2010).

CD44 induces changes in intracellular calcium in sensory neurons, increasing the excitability mediated by Src and focal adhesion kinase (Ghosh et al., 2011). While Src is involved in LMWH-induced hyperalgesia (Ferrari et al., 2016a), the Src inhibitor did not attenuate HMWH-induced antihyperalgesia.

The mechanisms by which HMWH antihyperalgesia is mediated in females by CD44, but not by TLR4 or RHAMM, has yet to be established. However, it is known that spinal TLR4 mediates hyperalgesia in male mice, but not in female mice, and while expression levels are not different, testosterone induces a switch in females to TLR4 dependence (Sorge et al., 2011).

We provide a schematic of the proposed signaling pathways that participate in HMWH-induced antihyperalgesia (Fig. 8). Our identification of a novel second messenger signaling pathway that reverses nociceptor sensitization opens a novel line of research into molecular targets for the treatment of pain syndromes that are dependent on nociceptor sensitization.

\section{References}

Alessandri-Haber N, Yeh JJ, Boyd AE, Parada CA, Chen X, Reichling DB, Levine JD (2003) Hypotonicity induces TRPV4-mediated nociception in rat. Neuron 39:497-511.

Altman RD, Moskowitz R (1998) Intraarticular sodium hyaluronate (Hyalgan) in the treatment of patients with osteoarthritis of the knee: a randomized clinical trial. Hyalgan Study Group. J Rheumatol 25:22032212.

Alvarez P, Green PG, Levine JD (2014) Role for monocyte chemoattractant protein-1 in the induction of chronic muscle pain in the rat. Pain 155:1161-1167.

Alvarez P, Bogen O, Green PG, Levine JD (2017) Nociceptor interleukin 10 receptor 1 is critical for muscle analgesia induced by repeated bouts of eccentric exercise in the rat. Pain 158:1481-1488.

Araldi D, Ferrari LF, Levine JD (2017) Hyperalgesic priming (type II) induced by repeated opioid exposure: maintenance mechanisms. Pain 158:1204-1216. 
Araldi D, Bogen O, Green PG, Levine JD (2019) Role of nociceptor Toll-like receptor 4 (TLR4) in opioid-induced hyperalgesia and hyperalgesic priming. J Neurosci 39:6414-6424.

Bogen O, Alessandri-Haber N, Chu C, Gear RW, Levine JD (2012) Generation of a pain memory in the primary afferent nociceptor triggered by PKC $\epsilon$ activation of CPEB. J Neurosci 32:2018-2026.

Borle AB, Snowdowne KW (1982) Measurement of intracellular free calcium in monkey kidney cells with aequorin. Science 217:252-254.

Bourguignon LY (2014) Matrix hyaluronan-activated CD44 signaling promotes keratinocyte activities and improves abnormal epidermal functions. Am J Pathol 184:1912-1919.

Bourguignon LY, Zhu H, Shao L, Chen YW (2000) CD44 interaction with tiam1 promotes Rac1 signaling and hyaluronic acid-mediated breast tumor cell migration. J Biol Chem 275:1829-1838.

Bourguignon LY, Singleton PA, Zhu H, Diedrich F (2003) Hyaluronan-mediated CD44 interaction with RhoGEF and Rho kinase promotes Grb2associated binder-1 phosphorylation and phosphatidylinositol 3-kinase signaling leading to cytokine (macrophage-colony stimulating factor) production and breast tumor progression. J Biol Chem 278:29420-29434.

Bourguignon LY, Shiina M, Li JJ (2014) Hyaluronan-CD44 interaction promotes oncogenic signaling, microRNA functions, chemoresistance, and radiation resistance in cancer stem cells leading to tumor progression. Adv Cancer Res 123:255-275.

Burch RM, Axelrod J (1987) Dissociation of bradykinin-induced prostaglandin formation from phosphatidylinositol turnover in Swiss 3T3 fibroblasts: evidence for $\mathrm{G}$ protein regulation of phospholipase A2. Proc Natl Acad Sci U S A 84:6374-6378.

Campo GM, Avenoso A, Campo S, D'Ascola A, Nastasi G, Calatroni A (2010) Small hyaluronan oligosaccharides induce inflammation by engaging both toll-like-4 and CD44 receptors in human chondrocytes. Biochem Pharmacol 80:480-490.

Cohen MM, Altman RD, Hollstrom R, Hollstrom C, Sun C, Gipson B (2008) Safety and efficacy of intra-articular sodium hyaluronate (Hyalgan) in a randomized, double-blind study for osteoarthritis of the ankle. Foot Ankle Int 29:657-663.

Cowman MK, Schmidt TA, Raghavan P, Stecco A (2015) Viscoelastic properties of hyaluronan in physiological conditions. F1000Res 4:622.

Cuff CA, Kothapalli D, Azonobi I, Chun S, Zhang Y, Belkin R, Yeh C, Secreto A, Assoian RK, Rader DJ, Puré E (2001) The adhesion receptor $\mathrm{CD} 44$ promotes atherosclerosis by mediating inflammatory cell recruitment and vascular cell activation. J Clin Invest 108:1031-1040.

Donatello S, Babina IS, Hazelwood LD, Hill AD, Nabi IR, Hopkins AM (2012) Lipid raft association restricts CD44-ezrin interaction and promotion of breast cancer cell migration. Am J Pathol 181:2172-2187.

Dougados M, Nguyen M, Listrat V, Amor B (1993) High molecular weight sodium hyaluronate (hyalectin) in osteoarthritis of the knee: a 1 year placebo-controlled trial. Osteoarthr Cartil 1:97-103.

Elmorsy S, Funakoshi T, Sasazawa F, Todoh M, Tadano S, Iwasaki N (2014) Chondroprotective effects of high-molecular-weight cross-linked hyaluronic acid in a rabbit knee osteoarthritis model. Osteoarthritis Cartilage 22:121-127.

England S, Bevan S, Docherty RJ (1996) PGE2 modulates the tetrodotoxinresistant sodium current in neonatal rat dorsal root ganglion neurones via the cyclic AMP-protein kinase A cascade. J Physiol 495:429-440.

Ferrari LF, Araldi D, Bogen O, Levine JD (2016a) Extracellular matrix hyaluronan signals via its CD44 receptor in the increased responsiveness to mechanical stimulation. Neuroscience 324:390-398.

Ferrari LF, Khomula EV, Araldi D, Levine JD (2016b) Marked sexual dimorphism in the role of the ryanodine receptor in a model of pain chronification in the rat. Sci Rep 6:31221.

Ferrari LF, Khomula EV, Araldi D, Levine JD (2018) CD44 signaling mediates high molecular weight hyaluronan-induced antihyperalgesia. J Neurosci 38:308-321.

Foger N, Marhaba R, Zoller M (2001) Involvement of CD44 in cytoskeleton rearrangement and raft reorganization in T cells. J Cell Sci 114:11691178.

Furuta J, Ariyoshi W, Okinaga T, Takeuchi J, Mitsugi S, Tominaga K, Nishihara T (2017) High molecular weight hyaluronic acid regulates MMP13 expression in chondrocytes via DUSP10/MKP5. J Orthop Res 35:331-339.
Ghatak S, Misra S, Toole BP (2005) Hyaluronan constitutively regulates ErbB2 phosphorylation and signaling complex formation in carcinoma cells. J Biol Chem 280:8875-8883.

Ghosh B, Li Y, Thayer SA (2011) Inhibition of the plasma membrane $\mathrm{Ca}^{2+}$ pump by $\mathrm{CD} 44$ receptor activation of tyrosine kinases increases the action potential afterhyperpolarization in sensory neurons. J Neurosci 31:2361-2370

Gold MS, Levine JD, Correa AM (1998) Modulation of TTX-R INa by PKC and PKA and their role in PGE2-induced sensitization of rat sensory neurons in vitro. J Neurosci 18:10345-10355.

Gomis A, Miralles A, Schmidt RF, Belmonte C (2007) Nociceptive nerve activity in an experimental model of knee joint osteoarthritis of the guinea pig: effect of intra-articular hyaluronan application. Pain 130:126-136.

Harper AA, Lawson SN (1985) Conduction velocity is related to morphological cell type in rat dorsal root ganglion neurones. J Physiol 359:31-46.

Huang TL, Chang CC, Lee CH, Chen SC, Lai CH, Tsai CL (2011) Intra-articular injections of sodium hyaluronate (Hyalgan $(\mathrm{R}))$ in osteoarthritis of the knee. a randomized, controlled, double-blind, multicenter trial in the Asian population. BMC Musculoskelet Disord 12:221.

Ito T, Williams JD, Fraser DJ, Phillips AO (2004) Hyaluronan regulates transforming growth factor-betal receptor compartmentalization. J Biol Chem 279:25326-25332.

Johnson P, Arif AA, Lee-Sayer SSM, Dong Y (2018) Hyaluronan and its interactions with immune cells in the healthy and inflamed lung. Front Immunol 9:2787.

Karousou E, Misra S, Ghatak S, Dobra K, Götte M, Vigetti D, Passi A, Karamanos NK, Skandalis SS (2017) Roles and targeting of the HAS/hyaluronan/CD44 molecular system in cancer. Matrix Biol 59:3-22.

Kataoka Y, Ariyoshi W, Okinaga T, Kaneuji T, Mitsugi S, Takahashi T, Nishihara T (2013) Mechanisms involved in suppression of ADAMTS4 expression in synoviocytes by high molecular weight hyaluronic acid. Biochem Biophys Res Commun 432:580-585.

Kawana H, Karaki H, Higashi M, Miyazaki M, Hilberg F, Kitagawa M, Harigaya K (2008) CD44 suppresses TLR-mediated inflammation. J Immunol 180:4235-4245.

Khomula EV, Ferrari LF, Araldi D, Levine JD (2017) Sexual dimorphism in a reciprocal interaction of ryanodine and IP3 receptors in the induction of hyperalgesic priming. J Neurosci 37:2032-2044

Khomula EV, Araldi D, Levine JD (2019) In vitro nociceptor neuroplasticity associated with in vivo opioid-induced hyperalgesia. J Neurosci 39:70617073.

Lee JL, Wang MJ, Sudhir PR, Chen JY (2008) CD44 engagement promotes matrix-derived survival through the CD44-SRC-integrin axis in lipid rafts. Mol Cell Biol 28:5710-5723.

Leinders M, Koehrn FJ, Bartok B, Boyle DL, Shubayev V, Kalcheva I, Yu NK, Park J, Kaang BK, Hefferan MP, Firestein GS, Sorkin LS (2014) Differential distribution of PI3K isoforms in spinal cord and dorsal root ganglia: potential roles in acute inflammatory pain. Pain 155:1150-1160.

Lennon FE, Singleton PA (2011) Role of hyaluronan and hyaluronan-binding proteins in lung pathobiology. Am J Physiol Lung Cell Mol Physiol 301: L137-L147.

Lesley J, Hascall VC, Tammi M, Hyman R (2000) Hyaluronan binding by cell surface CD44. J Biol Chem 275:26967-26975.

Liang J, Jiang D, Griffith J, Yu S, Fan J, Zhao X, Bucala R, Noble PW (2007) $\mathrm{CD} 44$ is a negative regulator of acute pulmonary inflammation and lipopolysaccharide-TLR signaling in mouse macrophages. J Immunol 178:2469-2475

Louderbough JM, Schroeder JA (2011) Understanding the dual nature of CD44 in breast cancer progression. Mol Cancer Res 9:1573-1586.

McKee CM, Penno MB, Cowman M, Burdick MD, Strieter RM, Bao C, Noble PW (1996) Hyaluronan (HA) fragments induce chemokine gene expression in alveolar macrophages. The role of HA size and CD44. J Clin Invest 98:2403-2413.

Mestre C, Pélissier T, Fialip J, Wilcox G, Eschalier A (1994) A method to perform direct transcutaneous intrathecal injection in rats. J Pharmacol Toxicol Methods 32:197-200.

Mizrahy S, Raz SR, Hasgaard M, Liu H, Soffer-Tsur N, Cohen K, Dvash R, Landsman-Milo D, Bremer MG, Moghimi SM, Peer D (2011) Hyaluronan-coated nanoparticles: the influence of the molecular weight on CD44-hyaluronan interactions and on the immune response. J Control Release 156:231-238. 
Murai T (2015) Lipid raft-mediated regulation of hyaluronan-CD44 interactions in inflammation and cancer. Front Immunol 6:420.

Oliveira-Fusaro MCG, Zanoni CIS, Dos Santos GG, Manzo LP, Araldi D, Bonet IJM, Tambeli CH, Dias EV, Parada CA (2017) Antihyperalgesic effect of $\mathrm{CB} 1$ receptor activation involves the modulation of $\mathrm{P} 2 \mathrm{X} 3$ receptor in the primary afferent neuron. Eur J Pharmacol 798:113-121.

Padmanabhan J, Gonzalez AL (2012) The effects of extracellular matrix proteins on neutrophil-endothelial interaction-a roadway to multiple therapeutic opportunities. Yale J Biol Med 85:167-185.

Parada CA, Yeh JJ, Reichling DB, Levine JD (2003) Transient attenuation of protein kinase $\mathrm{C} \epsilon$ can terminate a chronic hyperalgesic state in the rat. Neuroscience 120:219-226.

Qian H, Xia L, Ling P, Waxman S, Jing Y (2012) CD44 ligation with A3D8 antibody induces apoptosis in acute myeloid leukemia cells through binding to CD44s and clustering lipid rafts. Cancer Biol Ther 13:1276-1283.

Quanhong Z, Ying X, Moxi C, Tao X, Jing W, Xin Z, Li W, Derong C, Xiaoli $Z$, Wei J (2012) Intrathecal $\operatorname{PLC}(\beta 3)$ oligodeoxynucleotides antisense potentiates acute morphine efficacy and attenuates chronic morphine tolerance. Brain Res 1472:38-44.

Radin EL, Swann DA, Weisser PA (1970) Separation of a hyaluronate-free lubricating fraction from synovial fluid. Nature 228:377-378.

Randall LO, Selitto JJ (1957) A method for measurement of analgesic activity on inflamed tissue. Arch Int Pharmacodyn Ther 111:409-419.

Senbanjo LT, Chellaiah MA (2017) CD44: a multifunctional cell surface adhesion receptor is a regulator of progression and metastasis of cancer cells. Front Cell Dev Biol 5:18.

Song MJ, Wang YQ, Wu GC (2009) Additive anti-hyperalgesia of electroacupuncture and intrathecal antisense oligodeoxynucleotide to interleukin-1 receptor type I on carrageenan-induced inflammatory pain in rats. Brain Res Bull 78:335-341

Sorge RE, LaCroix-Fralish ML, Tuttle AH, Sotocinal SG, Austin JS, Ritchie J, Chanda ML, Graham AC, Topham L, Beggs S, Salter MW, Mogil JS (2011) Spinal cord Toll-like receptor 4 mediates inflammatory and neuropathic hypersensitivity in male but not female mice. J Neurosci 31:15450-15454.

Su L, Wang C, Yu YH, Ren YY, Xie KL, Wang GL (2011) Role of TRPM8 in dorsal root ganglion in nerve injury-induced chronic pain. BMC Neurosci 12:120.

Summer GJ, Romero-Sandoval EA, Bogen O, Dina OA, Khasar SG, Levine JD (2008) Proinflammatory cytokines mediating burn-injury pain. Pain 135:98-107.

Sun JL, Xiao C, Lu B, Zhang J, Yuan XZ, Chen W, Yu LN, Zhang FJ, Chen G, Yan M (2013) CX3CL1/CX3CR1 regulates nerve injury-induced pain hypersensitivity through the ERK5 signaling pathway. J Neurosci Res 91:545-553.

Taiwo YO, Levine JD (1989) Prostaglandin effects after elimination of indirect hyperalgesic mechanisms in the skin of the rat. Brain Res 492:397399.

Taiwo YO, Bjerknes LK, Goetzl EJ, Levine JD (1989) Mediation of primary afferent peripheral hyperalgesia by the cAMP second messenger system. Neuroscience 32:577-580.

Tammi R, MacCallum D, Hascall VC, Pienimäki JP, Hyttinen M, Tammi M (1998) Hyaluronan bound to CD44 on keratinocytes is displaced by hyaluronan decasaccharides and not hexasaccharides. J Biol Chem 273:28878-28888

Tavianatou AG, Caon I, Franchi M, Piperigkou Z, Galesso D, Karamanos NK (2019) Hyaluronan: molecular size-dependent signaling and biological functions in inflammation and cancer. FEBS J 286:2883-2908.
Taylor KR, Yamasaki K, Radek KA, Di Nardo A, Goodarzi H, Golenbock D, Beutler B, Gallo RL (2007) Recognition of hyaluronan released in sterile injury involves a unique receptor complex dependent on Toll-like receptor 4, CD44, and MD-2. J Biol Chem 282:18265-18275.

Toole BP (2009) Hyaluronan-CD44 interactions in cancer: paradoxes and possibilities. Clin Cancer Res 15:7462-7468.

Triantaffilidou K, Venetis G, Bika O (2013) Efficacy of hyaluronic acid injections in patients with osteoarthritis of the temporomandibular joint. A comparative study. J Craniofac Surg 24:2006-2009.

Tuhkanen AL, Tammi M, Pelttari A, Agren UM, Tammi R (1998) Ultrastructural analysis of human epidermal CD44 reveals preferential distribution on plasma membrane domains facing the hyaluronan-rich matrix pouches. J Histochem Cytochem 46:241-248.

Underhill C (1992) CD44: the hyaluronan receptor. J Cell Sci 103:293-298.

Unsworth A, Dowson D, Wright V (1975) Some new evidence on human joint lubrication. Ann Rheum Dis 34:277-285.

Vanhaesebroeck B, Guillermet-Guibert J, Graupera M, Bilanges B (2010) The emerging mechanisms of isoform-specific PI3K signalling. Nat Rev Mol Cell Biol 11:329-341.

Vigetti D, Karousou E, Viola M, Deleonibus S, De Luca G, Passi A (2014) Hyaluronan: biosynthesis and signaling. Biochim Biophys Acta 1840:2452-2459.

Wang Y, Abarbanell AM, Herrmann JL, Weil BR, Manukyan MC, Poynter JA, Meldrum DR (2010) TLR4 inhibits mesenchymal stem cell (MSC) STAT3 activation and thereby exerts deleterious effects on MSC-mediated cardioprotection. PLoS One 5:e14206.

Wang Y, Su L, Morin MD, Jones BT, Whitby LR, Surakattula MM, Huang H, Shi H, Choi JH, Wang KW, Moresco EM, Berger M, Zhan X, Zhang H, Boger DL, Beutler B (2016) TLR4/MD-2 activation by a synthetic agonist with no similarity to LPS. Proc Natl Acad Sci U S A 113:E884-E893.

Wight TN (2017) Provisional matrix: a role for versican and hyaluronan. Matrix Biol 60-61:38-56.

Wight TN (2018) A role for proteoglycans in vascular disease. Matrix Biol 71-72:396-420.

Woolf CJ, Ma Q (2007) Nociceptors-noxious stimulus detectors. Neuron 55:353-364

Wu PT, Kuo LC, Su FC, Chen SY, Hsu TI, Li CY, Tsai KJ, Jou IM (2017) High-molecular-weight hyaluronic acid attenuated matrix metalloproteinase-1 and -3 expression via CD44 in tendinopathy. Sci Rep 7:40840.

Wu SC, Chen CH, Wang JY, Lin YS, Chang JK, Ho ML (2018) Hyaluronan size alters chondrogenesis of adipose-derived stem cells via the CD44/ ERK/SOX-9 pathway. Acta Biomater 66:224-237.

Yamawaki H, Hirohata S, Miyoshi T, Takahashi K, Ogawa H, Shinohata R, Demircan K, Kusachi S, Yamamoto K, Ninomiya Y (2009) Hyaluronan receptors involved in cytokine induction in monocytes. Glycobiology 19:83-92.

Yang C, Cao M, Liu H, He Y, Xu J, Du Y, Liu Y, Wang W, Cui L, Hu J, Gao $\mathrm{F}$ (2012) The high and low molecular weight forms of hyaluronan have distinct effects on CD44 clustering. J Biol Chem 287:43094-43107.

Yang Z, Qin W, Chen Y, Yuan B, Song X, Wang B, Shen F, Fu J, Wang H (2018) Cholesterol inhibits hepatocellular carcinoma invasion and metastasis by promoting CD44 localization in lipid rafts. Cancer Lett 429:6677.

Zhang Z, Qin P, Deng Y, Ma Z, Guo H, Guo H, Hou Y, Wang S, Zou W, Sun Y, Ma Y, Hou W (2018) The novel estrogenic receptor GPR30 alleviates ischemic injury by inhibiting TLR4-mediated microglial inflammation. J Neuroinflammation 15:206. 